\title{
Relationship between microstructures and resistance in mafic assemblages that deform and transform
}

\author{
Nicolas Mansard ${ }^{1}$, Holger Stünitz ${ }^{1,2}$, Hugues Raimbourg ${ }^{1}$, Jacques Précigout ${ }^{1}$, Alexis Plunder ${ }^{3}$, and Lucille Nègre ${ }^{1}$ \\ ${ }^{1}$ Institut des Sciences de la Terre d'Orléans (ISTO), UMR 7327, CNRS/BRGM, Université d'Orléans, 45071 Orléans, France \\ ${ }^{2}$ Department of Geology, University of Troms $\varnothing$, Dramsveien 201, 9037 Troms $\varnothing$, Norway \\ ${ }^{3}$ BRGM, 45060 Orléans, France
}

Correspondence: Nicolas Mansard (nmansard@outlook.fr)

Received: 27 May 2020 - Discussion started: 5 June 2020

Revised: 24 September 2020 - Accepted: 4 October 2020 - Published: 18 November 2020

\begin{abstract}
Syn-kinematic mineral reactions play an important role for the mechanical properties of polymineralic rocks. Mineral reactions (i.e., nucleation of new phases) may lead to grain size reduction, producing fine-grained polymineralic mixtures, which have a strongly reduced viscosity because of the activation of grain-size-sensitive deformation processes. In order to study the effect of deformation-reaction feedback(s) on sample strength, we performed rock deformation experiments on "wet" assemblages of mafic compositions in a Griggs-type solid-medium deformation apparatus. Shear strain was applied at constant strain rate $\left(10^{-5} \mathrm{~s}^{-1}\right)$ and constant confining pressure $(1 \mathrm{GPa})$ with temperatures ranging from 800 to $900^{\circ} \mathrm{C}$. At low shear strain, the assemblages that react faster are significantly weaker than the ones that react more slowly, demonstrating that reaction progress has a first-order control on rock strength. With increasing strain, we document two contrasting microstructural scenarios: (1) the development of a single throughgoing high-strain zone of well-mixed, fine-grained aggregates, associated with a significant weakening after peak stress, and (2) the development of partially connected, nearly monomineralic shear bands without major weakening. The lack of weakening is caused by the absence of interconnected well-mixed aggregates of fine-grained reaction products. The nature of the reaction products, and hence the intensity of the mechanical weakening, is controlled by the microstructures of the reaction products to a large extent, e.g., the amount of amphibole and the phase distribution of reaction products. The samples with the largest amount of amphibole exhibit a larger grain size and show less weakening. In addition to their implications for the deformation of natural shear zones, our find-
\end{abstract}

ings demonstrate that the feedback between deformation and mineral reactions can lead to large differences in mechanical strength, even at relatively small initial differences in mineral composition.

\section{Introduction}

Mafic rocks constitute a large part of the oceanic crust and may be one of the main components of the lower continental crust (Rudnick and Fountain, 1995). The major constituents of mafic rocks, i.e., pyroxene and plagioclase, are mechanically strong minerals that show crystal plastic deformation only at high temperatures in natural systems (e.g., Rutter and Brodie, 1985; Brodie and Rutter, 1985, 1992). However, there are abundant examples of strongly deformed mafic rocks, even at relatively low temperatures, but invariably these rocks show metamorphic retrogression (Rutter and Brodie, 1985). For instance, concomitant deformation and metamorphism are observed along oceanic detachments, where deep levels of the oceanic mafic crust are exhumed (Harigane et al., 2008; Schroeder and John, 2004). Strongly sheared meta-gabbros are also present in exhumed subduction belts (Imon et al., 2004; Shelley, 1994; Soret et al., 2019) or in large-scale transcurrent shear zones (Jolivet and Miyashita, 1985; Shelley, 1994). In most cases, the decreasing temperature conditions during deformation result in coeval mineral reactions, often causing strong grain size reduction. The coupling between deformation and reaction is therefore essential to understand the process of strain localization, as observed in mafic mylonites (Brodie et al., 1992). 
The pyroxenes typically deform by crystal plasticity at high temperatures and high stresses (e.g., Borg and Handin, 1966; Coe, 1970; Coe and Kirby, 1975; Bystricky and Mackwell, 2001; Bystricky et al., 2016). Mechanical data from high-temperature deformation experiments with mafic rocks are relatively scarce (e.g., Dimanov et al., 2003, 2007; Dimanov and Dresen, 2005; Marti et al., 2017, 2018; Mansard et al., 2020), but the existing studies indicate that weakening processes are dependent on the "deformation history". The study of mylonitic deformation of natural mafic rocks provides insights, at small scale, into the deformation mechanisms and strain localization processes and, at large scale, into the strength of the lower crust (e.g., Rutter and Brodie, 1992; Kanagawa et al., 2008). There are two main mechanisms of rock deformation in the viscous deformation regime: (1) dislocation creep (crystal plasticity; e.g., Paterson, 2013) and (2) diffusion creep. The latter includes grain-scale diffusion creep, whereby diffusive mass transfer either occurs through the volume or phase boundaries of individual grains (e.g., Wheeler, 1992) and is the main strain-producing process, and diffusion-accommodated grain boundary sliding (GBS), whereby diffusive mass transfer adjusts grain shapes and asperities during cohesive, frictionless sliding (e.g., Ashby and Verrall, 1973; Paterson, 1990; Langdon, 2006, and references therein). If a fluid is involved and material is dissolved and reprecipitated, the process is often referred to as dissolution-precipitation creep (DPC). Grain boundary sliding and diffusive mass transfer are both always involved, so the terms diffusion creep and DPC are collective terms involving GBS and diffusive mass transfer. Diffusion creep is a grain-size-sensitive (GSS) deformation mechanism and may operate at low or high temperature, as well as typically at low stresses (e.g., Paterson, 1995).

Many researchers have pointed out the close relationship between strain or reaction-dependent grain size reduction and the activation of GSS creep in a variety of mafic assemblages (e.g., Kruse and Stünitz, 1999; Kenkmann and Dresen, 2002; Baratoux et al., 2005; Kanagawa et al., 2008; Mehl and Hirth, 2008; Menegon et al., 2015; Okudaira et al., 2015; Degli Alessandrini et al., 2017). For this reason, grain size reduction is recognized as one of the most significant mechanisms that controls rheological properties (e.g., Elyaszadeh et al., 2018; Brodie and Rutter, 1987; Bercovici and Ricard, 2012; Montési, 2013, Platt, 2015). Grain-size-controlling processes usually include dynamic recrystallization (e.g., Schmid, 1982; Brodie and Rutter, 1987; Behrmann, 1985; Fliervoet and White, 1995; Vissers et al., 1997) and/or metamorphic reactions (e.g., Rubie, 1983; Fitz Gerald and Stünitz, 1993; Stünitz and Fitz Gerald, 1993; Newman et al., 1999), but while dynamic recrystallization is only considered to have transient mechanical effects (Brodie and Rutter, 1987), a small grain size can be stabilized by new phases in phase mixtures wherein grain growth is inhibited by the pinning of grain boundaries (e.g., Olgaard and Evans, 1986, 1988; Fliervoet et al., 1997; Herwegh et al., 2011; Her- wegh and Berger, 2004). Furthermore, phase separation and compositional layering commonly form or develop during crystal plastic deformation (dislocation creep) of minerals. During metamorphic reactions and nucleation of new phases, minerals are spatially rearranged so that fine-grained mixedphase zones and polyphase shear bands may develop (e.g., Stünitz and Tullis, 2001; De Ronde et al., 2004, 2005; Kilian et al., 2011; Platt, 2015; Mansard et al., 2018, 2020). Such a spatial rearrangement controls the bulk strength of the rock, particularly when these phases have a large mechanical contrast. In particular, the interconnection of weak materials is necessary to induce a significant drop in bulk strength (e.g., Jordan, 1988; Handy, 1994; Dell'Angelo and Tullis, 1996; Holyoke and Tullis, 2006a, b).

The principal objective of this contribution is to study the effect of initial rock composition on the feedback processes between reaction and deformation. To do so, we have performed rock deformation experiments on "wet" assemblages of plagioclase-pyroxene assemblages in a Griggstype solid-medium deformation apparatus. As representative of the lower crust, the starting material was composed of plagioclase (labradorite; plag) and either Mg-rich orthopyroxene (opx) (from peridotite) or Fe-rich opx (from a granulitefacies anorthosite) in order to investigate the effect of different mineral compositions on rock deformation. In this system, the opx deformation properties are assumed to be the same for Mg- and Fe-rich opx. We also performed deformation experiments on amphibole (amph) + plag and pure amph assemblages at similar conditions to extend the study to typical amphibolite facies conditions. All these assemblages were deformed to varying amounts of strain, including at the early stages of deformation. These early stages can be challenging to access when studying natural cases because of successive overprints of deformation stages. In this contribution, we suggest that viscous strain localization is primarily dependent on the ability of minerals to react and that the feedback between deformation and mineral reactions can lead to large differences in mechanical strength and deformation processes.

\section{Methods}

\subsection{Experimental procedures}

\subsubsection{Starting material and sample preparation}

We have performed a series of shear deformation experiments in two Griggs-type deformation apparatuses at the University of Troms $\varnothing$ (Norway) and at the University of Orléans (France). Experiments were conducted on mineral powders separated from natural materials. Four different starting materials were prepared from different mineral sources: (1) gem-quality labradorite $\left(\mathrm{An}_{60}-\mathrm{Ab}_{38}-\mathrm{Or}_{2}\right)$ from Sonora (Mexico) mixed with orthopyroxene $\left(\mathrm{Wo}_{1}-\right.$ 


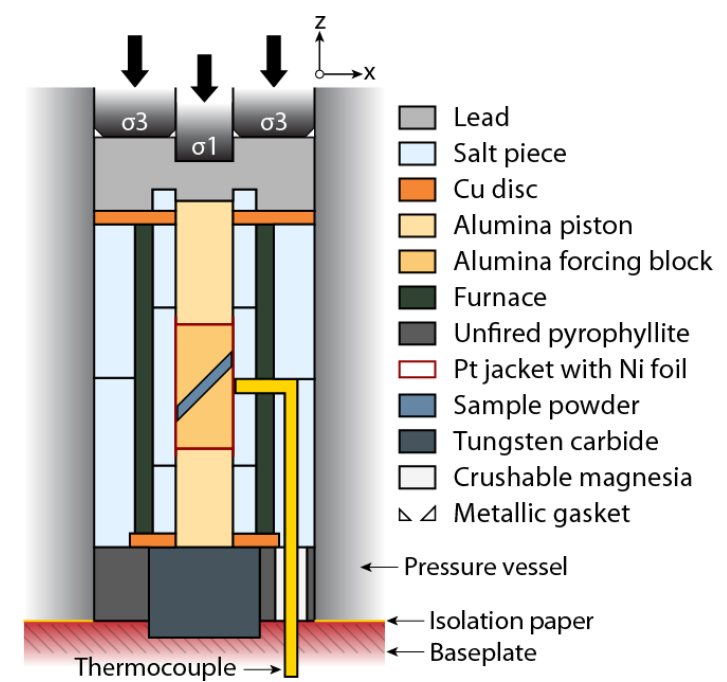

Figure 1. Drawing of the sample assembly in the Griggs-type apparatus.

$\mathrm{En}_{88}-\mathrm{Fs}_{11}$ ) from Damaping peridote (China), here referred to as $\mathrm{Mg}$-opx; (2) labradorite $\left(\mathrm{An}_{55}-\mathrm{Ab}_{44}-\mathrm{Or}_{1}\right)$ mixed with orthopyroxene $\left(\mathrm{Wo}_{2}-\mathrm{En}_{62}-\mathrm{Fs}_{36}\right)$ from Hidaka granulite (Japan), here referred to as Fe-opx; (3) amphibole (Mg-rich hornblende; composition available in Table 1) from the Massif Central (France) mixed with Sonora labradorite; and (4) pure Mg-rich hornblende. The pre-separated minerals were crushed in an alumina mortar, then sieved to $<100 \mu \mathrm{m}$, handpicked, and finally sorted in a distilled water column to obtain grain sizes between 10 and $20 \mu \mathrm{m}$. Powders were mixed in a $50: 50$ vol. \% ratio in acetone using an ultrasonic stirrer to avoid density and/or grain size separation (De Ronde et al., 2004, 2005).

To perform experiments, we used a conventional solid-salt, non-coaxial ("general shear") sample assembly with alumina pistons (Précigout et al., 2018). After adding $0.1 \mathrm{wt}$. \% of distilled $\mathrm{H}_{2} \mathrm{O}$, the powder was placed between alumina forcing blocks along a $45^{\circ}$ precut so that a shear zone $\sim 1 \mathrm{~mm}$ thick is formed when the deformation experiment starts (Fig. 1). The assembly was wrapped into a nickel foil $25 \mu \mathrm{m}$ thick and then inserted into a weld-sealed platinum jacket. $\mathrm{NaCl}$ pieces were used as solid confining medium for both the inner and outer furnace assembly. The temperature was measured by S-type ( $\mathrm{Pt} / \mathrm{Pt}-\mathrm{Rh})$ thermocouples centered on the sample. Readers are invited to refer to Pec et al. (2012b) and Précigout et al. (2018) for further details and descriptions of sample assemblies and experimental protocols employed.

\subsubsection{Experiments and mechanical data processing}

Deformation experiments were conducted at a constant shear strain rate of $\sim 2 \times 10^{-5} \mathrm{~s}^{-1}$ to varying amounts of shear strain (see Table 2 for a summary of experimental conditions), at temperatures of 800,850 , and $900^{\circ} \mathrm{C}$, and at a con- fining pressure of $1 \mathrm{GPa}$. To bring the samples to the desired pressure-temperature $(P-T)$ conditions, both the $\sigma_{1}$ and $\sigma_{3}$ pistons are alternatingly advanced between steps of increasing temperature. At the desired $P-T$ conditions, a period of hydrostatic hot-pressing was applied, and the deformation was started by advancing the $\sigma_{1}$ piston first through the lead piece ("lead run-in") to bring it into contact with the upper forcing block (hit point). During the lead run-in stage, the sample is maintained in a more or less isostatic stress state, as the lead protects the sample from becoming deformed. Two series of experiments on Mg-rich opx-bearing assemblages have been performed: one series with a short run-in period and a second one with a longer period (Table 2).

At the end of experiments, samples were quenched to $200^{\circ} \mathrm{C}$ within 2 to $3 \min \left(\sim 150\right.$ to $300^{\circ} \mathrm{C}$ per minute $)$ so that the deformation microstructures and grain size were preserved. Subsequently, the force and confining pressure were decreased simultaneously to room pressure and temperature conditions. During initial stages of the decompression, the differential stress is kept above the confining pressure $(\sim 100$ to $200 \mathrm{MPa}$ ) to reduce the formation of unloading cracks.

Experimental data were acquired and recorded using catman ${ }^{\circledR}$ Easy and then processed after the experiment with a MATLAB-based program following the "rig" program of Matej Pec (Pec et al., 2016; available at https://sites.google. $\mathrm{com} /$ site/jacquesprecigout/telechargements-downloads, last access: 21 March 2020). The hit point is defined by intersecting the run-in and loading curve tangent lines. After this point, several corrections are then applied to consider the rig distortion and changes in thickness and surface due to the sample compaction and piston overlap, respectively. The corrected mechanical data are represented in stress vs. strain graphs from the hit point.

\subsection{Analytical methods}

Double-polished thick sections $(\sim 150-200 \mu \mathrm{m})$ of the starting materials were prepared for Fourier transform infrared (FTIR) analysis. Thick sections were prepared from mineral powders for the Mg-rich opx + plag sample and from a natural section of mylonite for the Fe-rich opx + plag sample. For each sample, only grains larger than $100 \mu \mathrm{m}$ were used for FTIR analysis. Infrared absorption spectra were collected for Mg-opx, Fe-opx, and plag using a Nicolet 6700 FTIR instrument at the ISTO (Orléans, France); 128 scans were acquired for each spectrum at a resolution of $4 \mathrm{~cm}^{-1}$ with a spot size of $40 \times 40 \mu \mathrm{m}^{2}$. Only grain interiors were analyzed by FTIR. The integrated areas of the absorption bands measured between 3750 and $3000 \mathrm{~cm}^{-1}$ were used to calculate the $\mathrm{H}_{2} \mathrm{O}$ contents using the calibration of Bell et al. (1995) for opx and of Johnson and Rossmann (2003) for plag.

After the experiments, samples were cut parallel to the shear direction and impregnated under vacuum with lowviscosity epoxy to prepare thin sections. Sample microstructures were analyzed using a scanning electron microscope 
Table 1. Chemical compositions of plagioclase, pyroxene, and amphibole starting materials.

\begin{tabular}{|c|c|c|c|c|}
\hline & \multicolumn{2}{|c|}{ Sonora plag } & \multicolumn{2}{|c|}{ Damaping Mg-opx } \\
\hline & wt. \% oxides & Ions per 80 & wt. $\%$ oxides & Ions per 60 \\
\hline $\mathrm{SiO}_{2}$ & 53.87 & 2.434 & 55.71 & 1.929 \\
\hline $\mathrm{Al}_{2} \mathrm{O}_{3}$ & 29.41 & 1.566 & 3.81 & 0.155 \\
\hline $\mathrm{CaO}$ & 11.68 & 0.565 & 0.42 & 0.016 \\
\hline $\mathrm{Na}_{2} \mathrm{O}$ & 4.06 & 0.356 & 0.07 & 0.005 \\
\hline $\mathrm{K}_{2} \mathrm{O}$ & 0.46 & 0.027 & 0.02 & 0.001 \\
\hline $\mathrm{MgO}$ & 0.09 & 0.006 & 32.51 & 1.678 \\
\hline $\mathrm{TiO}_{2}$ & 0.08 & 0.003 & 0.07 & 0.002 \\
\hline $\mathrm{FeO}$ & 0.38 & 0.014 & 7.21 & 0.209 \\
\hline $\mathrm{MnO}$ & 0.05 & 0.002 & 0.18 & 0.005 \\
\hline \multirow[t]{6}{*}{ Total } & 100.08 & 4.972 & 100.01 & 4.000 \\
\hline & \multicolumn{2}{|c|}{ An60 } & \multicolumn{2}{|c|}{ Wo1 } \\
\hline & \multicolumn{2}{|c|}{$\mathrm{Ab} 38$} & \multicolumn{2}{|c|}{ En88 } \\
\hline & \multicolumn{2}{|c|}{ Or2 } & \multicolumn{2}{|c|}{ Fs11 } \\
\hline & \multicolumn{2}{|c|}{ Hidaka plag } & \multicolumn{2}{|c|}{ Hidaka Fe-opx } \\
\hline & wt. \% oxides & Ions per 80 & wt. $\%$ oxides & Ions per $6 \mathrm{O}$ \\
\hline $\mathrm{SiO}_{2}$ & 54.71 & 2.448 & 52.86 & 1.952 \\
\hline $\mathrm{Al}_{2} \mathrm{O}_{3}$ & 29.28 & 1.544 & 1.00 & 0.044 \\
\hline $\mathrm{CaO}$ & 11.42 & 0.548 & 1.23 & 0.049 \\
\hline $\mathrm{Na}_{2} \mathrm{O}$ & 4.94 & 0.429 & 0.06 & 0.004 \\
\hline $\mathrm{K}_{2} \mathrm{O}$ & 0.22 & 0.013 & 0.02 & 0.001 \\
\hline $\mathrm{MgO}$ & 0.01 & 0.001 & 22.41 & 1.234 \\
\hline $\mathrm{TiO}_{2}$ & 0.00 & 0.000 & 0.21 & 0.006 \\
\hline $\mathrm{FeO}$ & 0.39 & 0.015 & 22.55 & 0.696 \\
\hline $\mathrm{MnO}$ & 0.09 & 0.003 & 0.46 & 0.014 \\
\hline \multirow[t]{6}{*}{ Total } & 100.06 & 5.000 & 100.80 & 4.000 \\
\hline & \multicolumn{2}{|c|}{ An55 } & \multicolumn{2}{|c|}{ Wo2 } \\
\hline & \multicolumn{2}{|c|}{$\mathrm{Ab} 44$} & \multicolumn{2}{|c|}{ En62 } \\
\hline & \multicolumn{2}{|c|}{ Or1 } & \multicolumn{2}{|c|}{ Fs36 } \\
\hline & \multicolumn{2}{|c|}{ Massif Central amph } & & \\
\hline & wt. \% oxides & Ions per 230 & & \\
\hline $\mathrm{SiO}_{2}$ & 43.99 & 6.646 & & \\
\hline $\mathrm{Al}_{2} \mathrm{O}_{3}$ & 9.91 & 1.765 & & \\
\hline $\mathrm{CaO}$ & 11.12 & 1.800 & & \\
\hline $\mathrm{Na}_{2} \mathrm{O}$ & 1.67 & 0.489 & & \\
\hline $\mathrm{K}_{2} \mathrm{O}$ & 0.47 & 0.091 & & \\
\hline $\mathrm{MgO}$ & 10.87 & 2.448 & & \\
\hline $\mathrm{TiO}_{2}$ & 1.21 & 0.138 & & \\
\hline $\mathrm{FeO}$ & 17.79 & 2.248 & & \\
\hline $\mathrm{MnO}$ & 0.38 & 0.000 & & \\
\hline \multirow[t]{2}{*}{ Total } & 97.41 & 15.625 & & \\
\hline & \multicolumn{2}{|c|}{ Magnesio-hornblende } & & \\
\hline
\end{tabular}

(SEM - TESCAN MIRA 3 XMU) at ISTO-BRGM (Orléans, France). All SEM analyses have been performed on carbon-coated ( $20 \mathrm{~nm}$ thickness) thin sections at $12-15 \mathrm{kV}$ and a working distance of $\sim 8 \mathrm{~mm}$. Mineral compositions were collected using a CAMECA SX Five electron micro- probe analyzer (EPMA) at ISTO-BRGM (Orléans, France). We adopted the following analytical condition: an acceleration voltage of $12-15 \mathrm{kV}$, a beam current of $\sim 6 \mathrm{nA}$, and a beam diameter of $\sim 1 \mu \mathrm{m}$. 
Table 2. List of experiments and experimental conditions. PS: peak stress, D: deformed samples to varying amounts of shear strain. A cross is added to the samples for which the forcing blocks started to slip at the sample interface. $\tau_{\text {peak }}$ : differential stress at peak, $\tau_{\text {flow }}$ : steady-state differential stress, $\tau_{\text {end }}$ : differential stress at end of experiment, $\gamma:$ shear strain, th ${ }_{0}:$ thickness initial of the shear zone, the final shear zone thickness, $t$ : time before hit point.

\begin{tabular}{|c|c|c|c|c|c|c|c|c|c|c|c|c|}
\hline Exp. no. & Material & Type & $\begin{array}{r}T \\
\left({ }^{\circ} \mathrm{C}\right)\end{array}$ & $\begin{array}{r}P \\
(\mathrm{Gpa})\end{array}$ & $\begin{array}{r}\mathrm{H}_{2} \mathrm{O} \\
(\mu \mathrm{L})\end{array}$ & $\begin{array}{r}\tau_{\text {peak }} \\
(\mathrm{MPa})\end{array}$ & $\begin{array}{r}\tau_{\text {flow }} \\
(\mathrm{MPa})\end{array}$ & $\begin{array}{r}\tau_{\text {end }} \\
(\mathrm{MPa})\end{array}$ & $\gamma$ & $\begin{array}{r}\mathrm{Th}_{0} \\
(\mathrm{~mm})\end{array}$ & $\begin{array}{r}\operatorname{th}_{\mathrm{f}} \\
(\mathrm{mm})\end{array}$ & $\begin{array}{r}t \\
\text { (h) }\end{array}$ \\
\hline $557 \mathrm{NM}$ & Mg-opx + plag & $\mathrm{PS}^{x}$ & 850 & 1 & 0.12 & 1067 & - & 577 & 0.4 & 0.75 & 0.59 & 35 \\
\hline $559 \mathrm{NM}$ & Mg-opx + plag & $\mathrm{PS}^{x}$ & 800 & 1 & 0.12 & 1111 & - & 350 & 0.5 & 0.75 & 0.67 & 38 \\
\hline OR24NM & Mg-opx + plag & $\mathrm{D}^{x}$ & 800 & 1 & 0.25 & 1280 & - & 866 & 3.1 & 1.1 & 0.87 & 85 \\
\hline OR34NM & Mg-opx + plag & $\mathrm{D}$ & 900 & 1 & 0.25 & 781 & 114 & 126 & 7.6 & 1.1 & 0.68 & 96 \\
\hline OR38NM & Mg-opx + plag & $\mathrm{D}$ & 850 & 1 & 0.25 & 1037 & 339 & 339 & 8.0 & 1.1 & 0.63 & 83 \\
\hline OR41NM & Mg-opx + plag & $\mathrm{D}$ & 900 & 1 & 0.25 & 1094 & 542 & 542 & 7.0 & 1.1 & 0.72 & 53 \\
\hline OR47NM & Mg-opx + plag & PS & 900 & 1 & 0.25 & 989 & - & 989 & 0.6 & 1.1 & 0.91 & 25 \\
\hline OR49NM & Mg-opx + plag & $\mathrm{D}^{x}$ & 900 & 1 & 0.25 & 1111 & 800 & 800 & 6.0 & 1.1 & 0.73 & 68 \\
\hline OR51NM & Mg-opx + plag & PS & 900 & 1 & 0.25 & 901 & - & 901 & 0.8 & 1.1 & 1 & 156 \\
\hline $532 \mathrm{NM}$ & Fe-opx + plag & $\mathrm{D}$ & 900 & 1 & 0.12 & - & - & 405 & 5.0 & 0.75 & 0.54 & 38 \\
\hline $533 \mathrm{NM}$ & Fe-opx + plag & $\mathrm{D}$ & 850 & 1 & 0.12 & 645 & 683 & 683 & 3.8 & 0.75 & 0.47 & 50 \\
\hline $538 \mathrm{NM}$ & Fe-opx + plag & $\mathrm{D}^{x}$ & 800 & 1 & 0.12 & 1080 & - & 563 & 0.9 & 0.75 & 0.73 & 28 \\
\hline OR61NM & Fe-opx + plag & PS & 850 & 1 & 0.25 & 885 & - & 897 & 1.7 & 1.1 & 0.73 & 77 \\
\hline OR15NM & amph & $\mathrm{D}$ & 900 & 1 & 0.20 & 348 & 147 & 147 & 3.7 & 0.9 & 0.62 & 104 \\
\hline OR18NM & amph & $\mathrm{D}$ & 800 & 1 & 0.20 & 803 & 370 & 370 & 5.4 & 0.9 & 0.68 & 73 \\
\hline OR23NM & amph + plag & $\mathrm{D}$ & 800 & 1 & 0.20 & 563 & 435 & 483 & 5.8 & 0.9 & 0.60 & 31 \\
\hline
\end{tabular}

Thin sections were additionally polished with colloidal silica and then coated with a thin carbon coat $\sim 2 \mathrm{~nm}$ thick for electron backscatter diffraction (EBSD) analysis. The EBSD analyzes were carried out using an EDAX PEGASUS EDS/EBSD system and the OIM DC 6.4 software (manufacturer EDAX; Mahwah, USA) at ISTO-BRGM (Orléans, France). The operating conditions involved an accelerating voltage of $20-25 \mathrm{kV}$ and a working distance of $15-18 \mathrm{~mm}$. Post-acquisition treatments, which include plotting equalarea lower-hemisphere pole figures of amphibole lattice preferred orientation (LPO), were performed using the opensource MTEX toolbox for MATLAB. For the definition of a grain, five adjacent indexed points were required. Texture strength is expressed through the $\mathrm{J}$ index and $\mathrm{M}$ index (Bunge, 1982; Skemer et al., 2005).

\subsection{Microstructural analysis}

SEM backscattered electron (BSE) images were used to produce manually digitized grain maps. Grain sizes were measured from these grain maps by using the public domain software ImageJ (http://rsb.info.nih.gov/ij/, last access: 11 March 2020). By extracting the area-equivalent diameter from these maps, the grain size is defined as the diameter of equivalent circular diameter $\left(d_{\text {equ }}=2 \times \sqrt{\frac{\text { area }}{\pi}}\right)$. From these grain maps, the grain shape preferred orientation (SPO) and the modal proportion of phases can be analyzed. In the case in which grain boundaries are indistinguishable within am- phibole aggregates, EBSD maps have been processed with MTEX to determine the grain size.

In order to estimate the proportion of phases we used SEM BSE images to produce manually digitized grain maps with the illustrator software when it was possible to distinguish the grain boundaries (e.g., Fe-rich opx + plag assemblages). From these phase maps we could separate the phases with the ImageJ software and estimate their proportion. This is how the amount of amphibole in the Fe-rich opx + plag assemblages is estimated. When it was impossible to distinguish the grains individually, we drew areas that corresponded either to a set of grains of the same phase or to several phases that could not be separated. Some grains are too small to be separated with enough confidence from other grains. For this reason, we have included all reaction products together and have not separated the amphibole from the plagioclase 2 and the pyroxene2 in the Mg-rich opx + plag assemblages.

\section{Results}

\subsection{Mechanical data}

Depending on the starting material, the mechanical data differ significantly with respect to each other (Fig. 2). At 850 and $900{ }^{\circ} \mathrm{C}$, the Mg-rich opx + plag samples (Fig. 2b-c) are characterized by a pronounced peak stress at shear strains of less than $\gamma \sim 1$, whereas the Fe-rich opx + plag ones do not show a pronounced peak stress but a steady-state flow after yield or, at $900^{\circ} \mathrm{C}$, a constant strain-hardening behav- 
ior (Fig. 2d). At $800^{\circ} \mathrm{C}$, the peak stresses of all opx + plag samples are above the Goetze criterion $\left(\Delta \sigma \leq P_{\text {conf }}\right)$, which provides an empirical upper limit for viscous creep. Above this limit, samples are expected to deform by brittle mechanisms (Kohlstedt et al., 1995). The abrupt stress drop in Ferich opx + plag samples at $800^{\circ} \mathrm{C}$ and short run-in samples at 800 and $850^{\circ} \mathrm{C}$ indicates that slip has occurred at the interface between the sample and one forcing block (Fig. 2b, d; 557NM, 559NM, and 538NM). The slip is confirmed by sample microstructures and suggests that peak stress might have been higher without the slip event. In contrast, two Mgrich opx + plag samples at $900^{\circ} \mathrm{C}$ show a pronounced strain weakening after peak stress. In one case, the sample falls substantially below the Goetze criterion as a result of slip along the forcing block interface and stabilizes around $800 \mathrm{MPa}$ (OR49NM). In the other case, the sample weakens continuously after peak stress and reaches almost steady state for $\gamma \sim 6.5$ (OR41NM). One way to vary the time of reaction in different experiments is to keep the sample at hydrostatic conditions at given pressure and temperature before starting to deform it (long or short run-in periods of the piston). In the experiments with longer run-in periods, the Mg-rich opx + plag assemblages weaken systematically after peak stress. They reach stresses lower than $400 \mathrm{MPa}$ at 850 and $900{ }^{\circ} \mathrm{C}$, corresponding to $\sim 64 \%$ (OR38NM) and $\sim 78 \%$ (OR34NM) of the peak stress before reaching a quasi-steadystate shear stress near $\gamma \sim 6.5$ for OR34NM and $\gamma \sim 7.7$ for OR38NM (Fig. 2c). At $850^{\circ} \mathrm{C}$, the Fe-rich opx + plag sample behavior is no longer comparable to that of the mixed Mg-rich assemblages, as no weakening occurs after peak stress and a quasi-steady-state shear stress is reached at low shear strain $(\gamma \sim 2)$. At $900^{\circ} \mathrm{C}$, the sample remains weak but hardens continuously until $\gamma \sim 5$, unlike the other experiments (Fig. 2d).

Compared to the opx + plag assemblages, the amph + plag and pure amph assemblages do not reach the same strength, regardless of the deformation temperature (Fig. 2e). At $800^{\circ} \mathrm{C}$, the amph + plag assemblage reaches a peak stress of $\sim 563 \mathrm{MPa}$ and then slightly weakens to $\sim 483 \mathrm{MPa}$ at $\gamma \sim 5.8$. The pure amph assemblages deformed at 800 and $900^{\circ} \mathrm{C}$ show stress-strain curves with a significant weakening after peak stress at $\gamma \sim 0.5$ to 1.0. However, the sample at $800^{\circ} \mathrm{C}$ documents a peak stress of $\sim 450 \mathrm{MPa}$ higher than the sample deformed at $900^{\circ} \mathrm{C}$.

Our set of experiments reveals two distinct types of mechanical behavior: one that shows a pronounced weakening after high peak stress (Mg-rich opx + plag and pure amph assemblages) and one without weakening (Fe-rich opx + plag and amph + plag assemblages) or even hardening (Fe-rich sample at $900^{\circ} \mathrm{C}, 532 \mathrm{NM}$; Fig. 2d) but that deforms at considerably lower stresses (all Fe-rich samples; Fig. 2d).

\subsection{Mineral reactions and microstructures}

Mineral reactions occur pervasively in deformed portions of the samples - there is a clear correlation between strain and reaction progress (Mansard et al., 2020). The pervasive occurrence of mineral reactions induces substantial changes in the grain size and spatial distribution of phases. This is particularly prominent in the development of shear bands within the deformed assemblages. For the sake of clarity, the term "bulk shear zone" refers to the whole sample deformed between the two alumina forcing blocks, while the term "shear bands" refers to a localized zone of variable thickness of high shear strain accommodation within the bulk shear zone. In addition, the term "high-strain zone" is also used to refer to the domain of coalescence of fine-grained shear bands that are connected as a more or less single zone through the bulk shear zone.

In the two main systems studied, the Fe-rich and Mg-rich opx + plag assemblages, the opx deformation features are the same. In these deformed assemblages, similar reaction products are observed, with the formation of amphibole, pyroxene, plagioclase, and, to a minor extent, quartz.

$\mathrm{opx}_{1}+\mathrm{plag}_{1}+\mathrm{H}_{2} \mathrm{O} \rightarrow \mathrm{amph}+\mathrm{opx}_{2}+\operatorname{plag}_{2} \pm \mathrm{cpx} \pm \mathrm{qtz}$

In these assemblages the mineral compositions were analyzed if the grain size was sufficiently large because in mixture zones, individual grains are typically too small to be analyzed. Thus, the very small grain size precludes an exact compositional analysis of the actual reaction products.

The Mg-rich opx + plag assemblages deformed to high shear strain are characterized by the development of lowstrain zones and a high-strain zone in the center of the bulk shear zone (Fig. 3a). Mineral reactions are localized within this single connected zone that traverses the sample from one interface of the forcing block to the other (at $850^{\circ} \mathrm{C}$; Fig. 3a) as fine-grained mixed zones and C-geometry shear bands subparallel to the shear plane (or forcing block interface; Figs. 4a-c, 5a-f). The C-type shear bands are mainly composed of fine $\mathrm{opx}_{2}$, $\mathrm{plag}_{2}$, and amph that are present as equant grains; their identification is possible by EDS analysis in the SEM (Fig. 4). The original large grains of plag 1 and $\mathrm{opx}_{1}$ form porphyroclasts embedded in a mixture of reaction products (Fig. 3a). In contrast to the high-strain zone, the reaction products in the low-strain zones usually occur as coronas or rims surrounding opx 1 clasts (Fig. $4 \mathrm{~d}-\mathrm{e}$ ). The main difference between the assemblages deformed at 850 and $900^{\circ} \mathrm{C}$ is the degree of strain localization. At $850{ }^{\circ} \mathrm{C}$, strain is highly localized in a $\sim 250-300 \mu \mathrm{m}$ wide single zone, while strain is more distributed throughout the sample at $900^{\circ} \mathrm{C}$, and therefore local strain appears lower. Otherwise, the microstructural features are similar to those of the high-strain zone (Fig. 4f-g).

At the scale of the bulk shear zone, both the Fe-rich opx + plag and amph + plag assemblages are banded and show a locally developed, nonconnected mylonitic foliation 


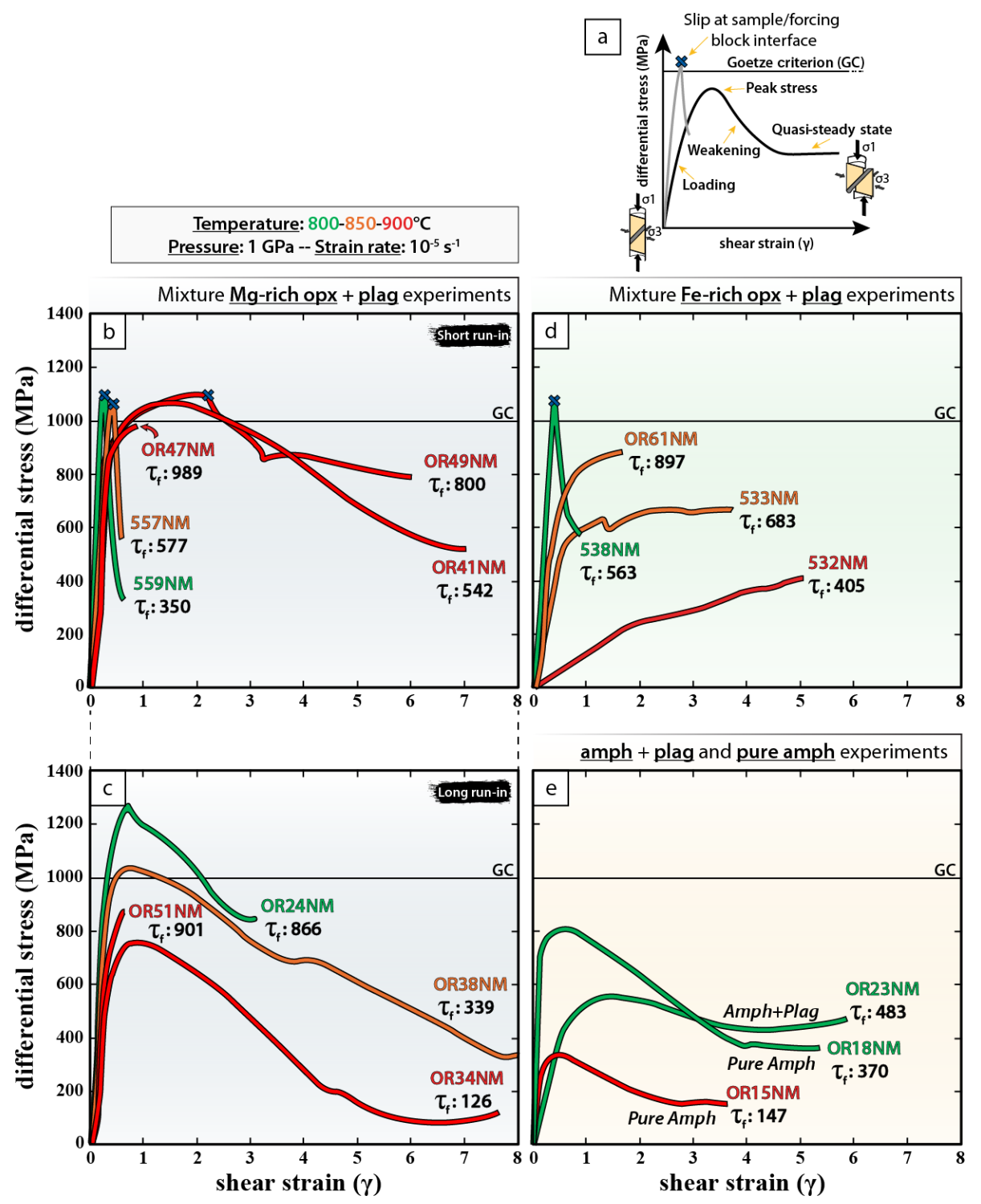

Figure 2. Mechanical data. (a) Terms used to describe the different stages of an experiment. (b-c) Differential stress (MPa) versus shear strain $(\gamma)$ showing the mechanical behavior of the Mg-rich opx + plag assemblages deformed at temperatures ranging from 800 to $900{ }^{\circ} \mathrm{C}$, at constant confining pressure of $1 \mathrm{GPa}$, and at a strain rate of $10^{-5} \mathrm{~s}^{-1}$. The difference between $(\mathbf{b})$ and $(\mathbf{c})$ is related to the different duration of the "run-in" section, i.e., time spent at $P-T$ conditions before the hit point. Mechanical data for Fe-rich opx + plag (d) as well as amph + plag and pure amph (e) assemblages are also plotted in stress-strain graphs. opx: orthopyroxene, pl: plagioclase, amph: amphibole.

characterized by the development of amph-rich shear bands and tails at $\mathrm{opx}_{1}$ porphyroclasts (Fig. $3 \mathrm{~b}-\mathrm{c}$ ). These bands wrap around the original and large opx 1 porphyroclasts in Fe-rich opx + plag assemblages (Fig. 3b) and in amph + plag assemblages (Fig. 3c). The reaction products in shear bands alternate with aggregates of original grains. The mylonitic foliation is better defined in the amph + plag assemblage because of more pervasive deformation and strain localization (Fig. 3c). The shear bands are more heterogeneously distributed in the Fe-rich opx + plag assemblage deformed at $850^{\circ} \mathrm{C}$ (Fig. 3b). This results in the development of an anastomosing network of amph-rich shear bands that are less con- nected (Fig. 3b), without forming any throughgoing highstrain zone (Fig. 3a).

The reaction products in the Fe-rich opx + plag assemblages contain less $\mathrm{opx}_{2}$ than the Mg-rich opx + plag assemblages, and amph $+\operatorname{plag}_{2}$ represents the main reaction products (Figs. $5 \mathrm{~g}-\mathrm{j}, 6$ ). From site to site in the Fe-rich opx + plag sample deformed at $850^{\circ} \mathrm{C}$, a variable proportion of opx and plag has reacted. Mineral reactions preferentially occur in strongly deformed areas and form only locally interconnected separate aggregates and shear bands consisting of amph $+\mathrm{opx}_{2} / \mathrm{cpx}$ or plag (Fig. 6a-b), while in less deformed areas, the reaction products typically occur 

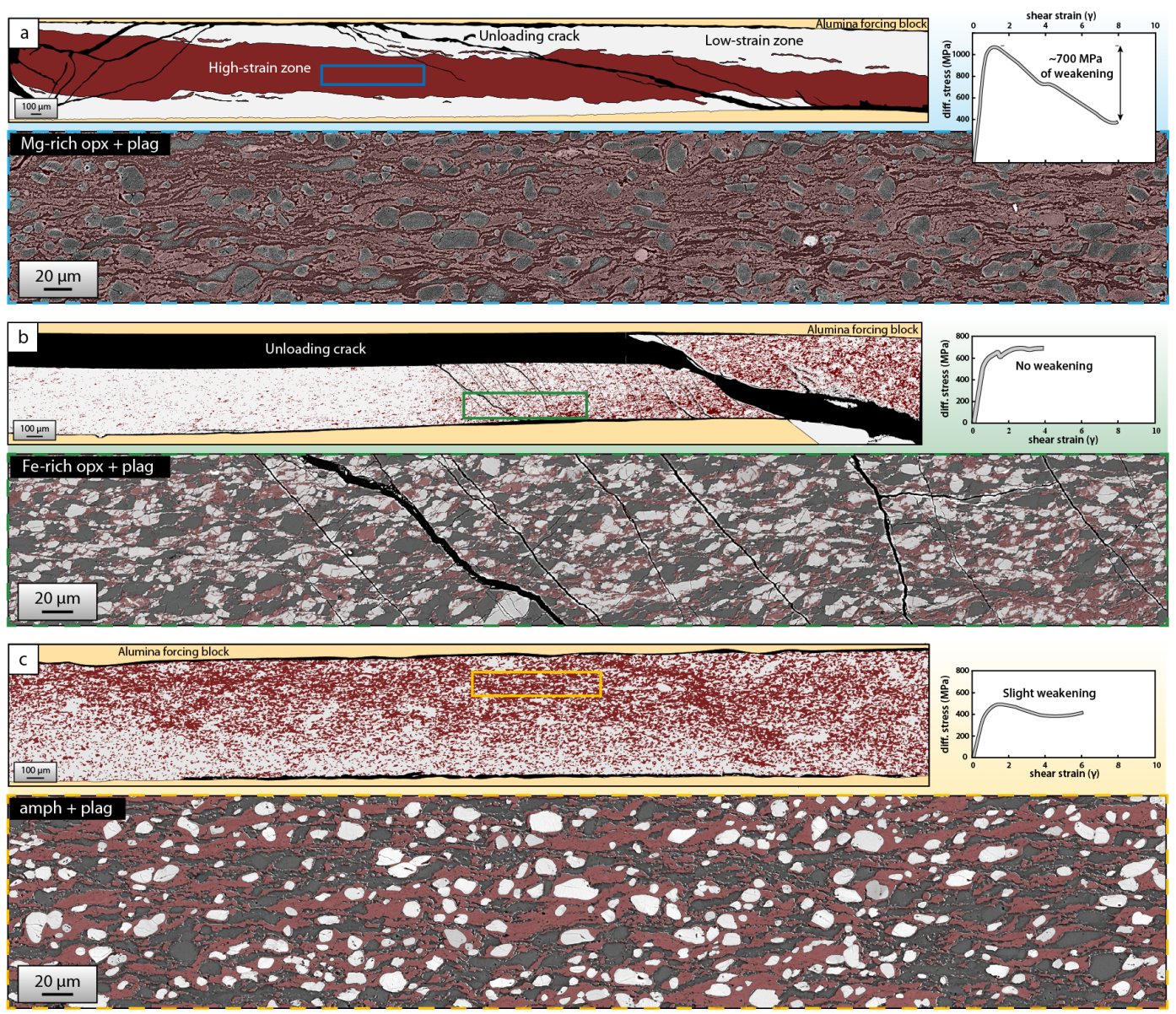

Figure 3. Distribution of reaction products after deformation in the Mg-rich opx + plag (a), Fe-rich opx + plag (b), and amph + plag $(\mathbf{c})$ assemblages. For each assemblage, a manually digitized overview of the shear zone is associated with a zoomed part of it. The mechanical data associated with these assemblages are also represented in stress-strain graphs.

as thick rims at grain boundaries of extensional sites of opx $\mathrm{x}_{1}$ and plag $_{1}$ clasts (Fig. 6c). The amph grains are elongated and typically form tails extending from $\mathrm{opx}_{1}$ porphyroclasts (Fig. 6b, c). At $900^{\circ} \mathrm{C}$, the Fe-rich opx + plag sample is more homogeneously deformed with a similar distribution of reaction products as observed at $850^{\circ} \mathrm{C}$ (Fig. 6d-e).

The amph + plag assemblage (Figs. 5k-1, 7a-c) deformed at $800{ }^{\circ} \mathrm{C}$ produced a large quantity of reaction products composed of $\mathrm{amph}_{2}$, $\mathrm{plag}_{2}$, clinopyroxene (cpx), and minor zoisite (zo). There is a spatial relationship between amph and cpx, the latter occurring as small grains, predominantly around amph porphyroclasts $\left(\mathrm{amph}_{1}\right)$ mixed with small grains of new $\mathrm{amph}_{2}$ (Fig. 7a-b). Unlike Fe-rich opx + plag assemblages, the shear bands involve several phases (amph and cpx) in the amph + plag assemblages (Fig. 5k-1). Regarding the pure amph assemblages deformed at 800 and $900^{\circ} \mathrm{C}$ (Figs. $5 \mathrm{~m}-\mathrm{n}, 7 \mathrm{~d}-\mathrm{e}$ ), mineral reactions are homogeneously distributed with the formation of $\mathrm{amph}_{2}$, cpx and minor zo, quartz (qtz), and garnet (grt). Reaction induces the development of mixture zones of $\operatorname{amph}_{2}$ and cpx and unmixed zones of grt, zo, and qtz (Fig. 5m-n). No melt was detected in the microstructures.

\subsection{Chemical composition}

The chemical composition of new grains is systematically different compared to that of the original ones. In each assemblage, the original plag $_{1}$ composition is An55-60. These grains are rimmed by more albite-rich plag $_{2}$ (An38-45 in Fe-rich opx + plag samples, An48-55 in Mg-rich opx + plag samples; Figs. 4, 5, 7, 8a-a' ${ }^{\prime}$. The fine grains in mixed zones are also more albite-rich than the starting plag 1 (Fig. 8a-a'). For the $\mathrm{opx}_{2}$, the ferrosilite content increases with respect to the original $\mathrm{opx}_{1}$, regardless of the original $\mathrm{opx}_{1}$ composition (Fig. 8b). The XMg ratio ranges between $\sim 0.85$ and $\sim 0.89$ in the Mg-rich opx 2 and between $\sim 0.64$ and $\sim 0.68$ in the Fe-rich $\mathrm{opx}_{2}\left(\right.$ with $\mathrm{XMg}=\mathrm{Mg} /\left(\mathrm{Mg}+\mathrm{Fe}^{2+}\right)$ ). The newly formed cpx in the amph + plag and pure amph assemblages has an augite composition (Fig. 8b). It is worth mentioning that the composition of the main reaction products (orthopyroxene and plagioclase) in the Fe-rich opx + plag 

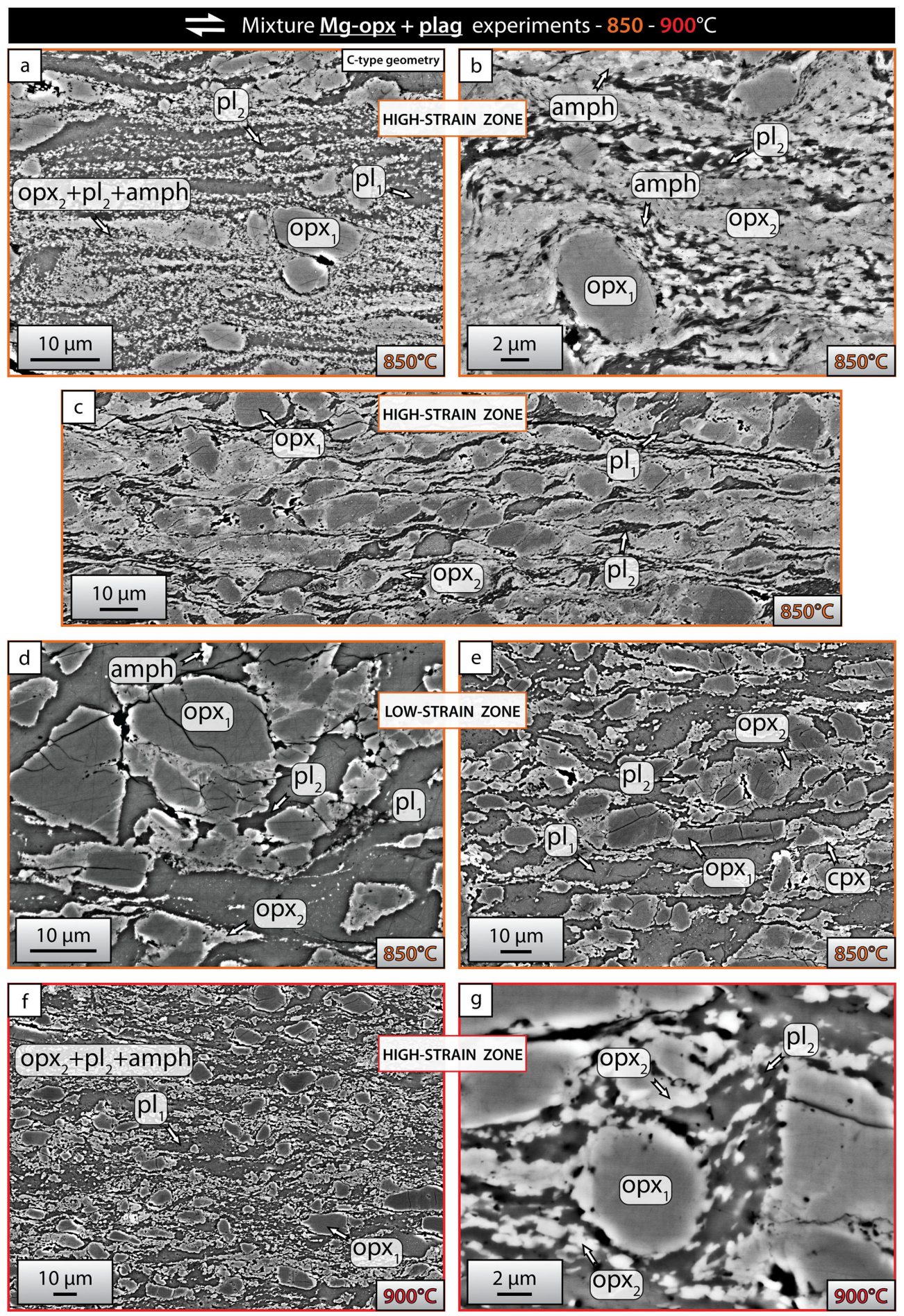

Figure 4. SEM BSE images representative of microstructures observed in deformed Mg-rich opx + plag assemblages; opx 2 and plag 2 are the main reaction products. (a-b) At $850^{\circ} \mathrm{C}$, mineral reactions are mainly localized in the high-strain zones in the form of fine-grained mixed zones. (c) The original plag 1 almost completely disappears. (d) In low-strain zones, the reaction products appear as coronas around the original opx 1 and as aggregates; (e) opx 1 is locally fractured and filled with reaction products. (f-g) Similar microstructures are observed at $900^{\circ} \mathrm{C}$, although deformation is less localized compared to the assemblage deformed at $850^{\circ} \mathrm{C}$. opx: orthopyroxene, pl: plagioclase, amph: amphibole. 

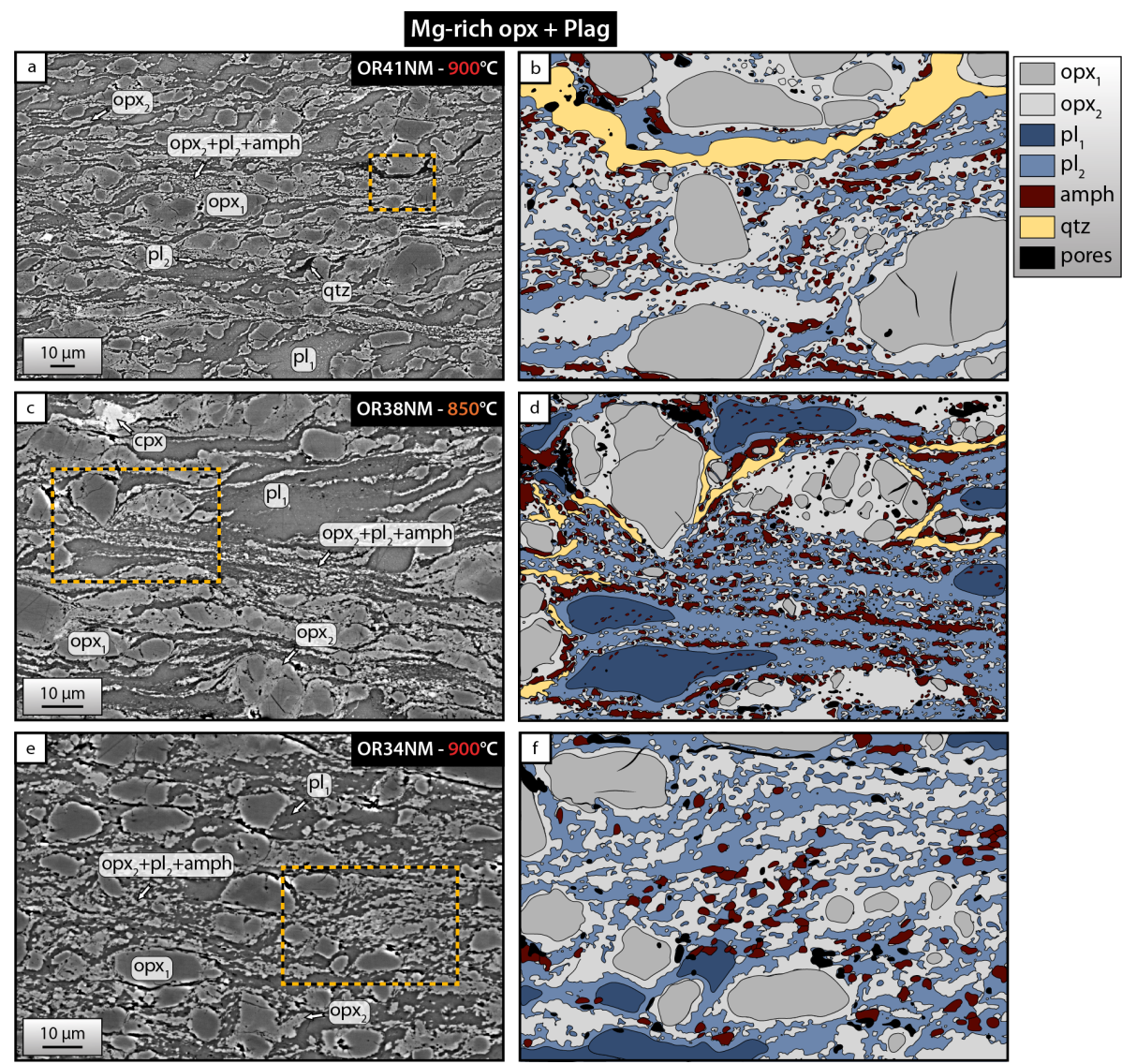

Fe-rich op + plag
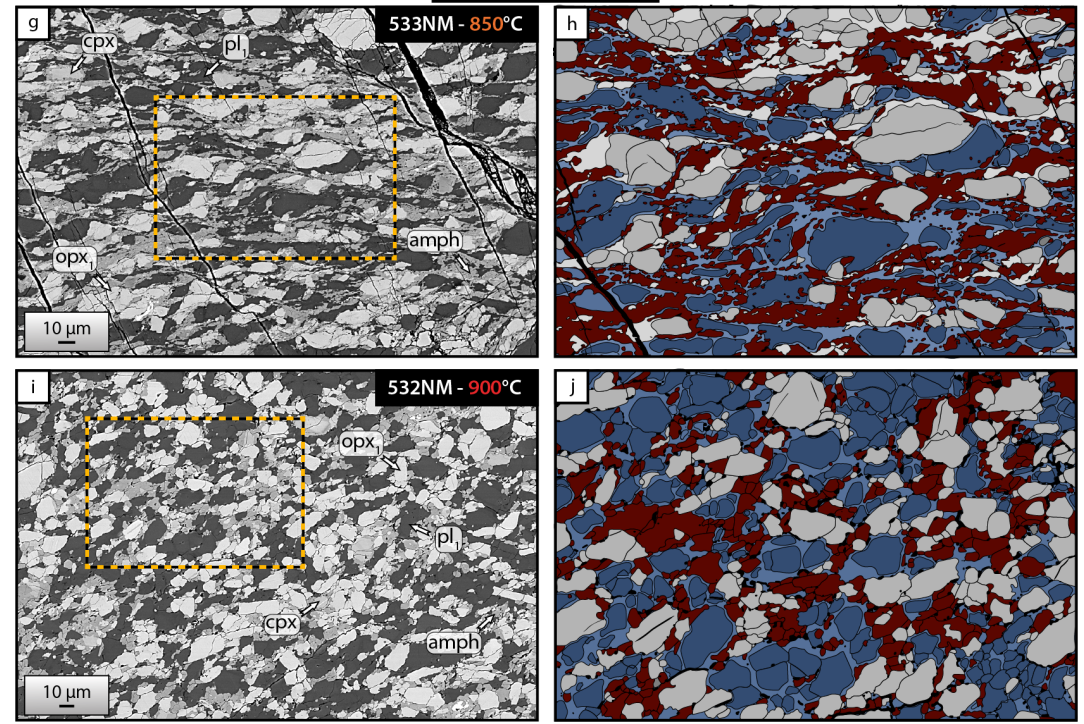

Figure 5.

assemblages are farther away from the starting composition compared to those of the Mg-rich opx + plag assemblages.

The composition of the original amph used in both amph + plag and pure amph experiments is not constant and varies in the magnesio-hornblende field (Fig. 8c). The newly formed amph for all assemblages has a composition ranging from magnesio-hornblende to tschermakite (Fig. 8c). There are nonetheless four chemically distinct populations of new amph, depending on the composition of the starting mixture, as shown in the plot of Si vs. XMg (Fig. 8c). 

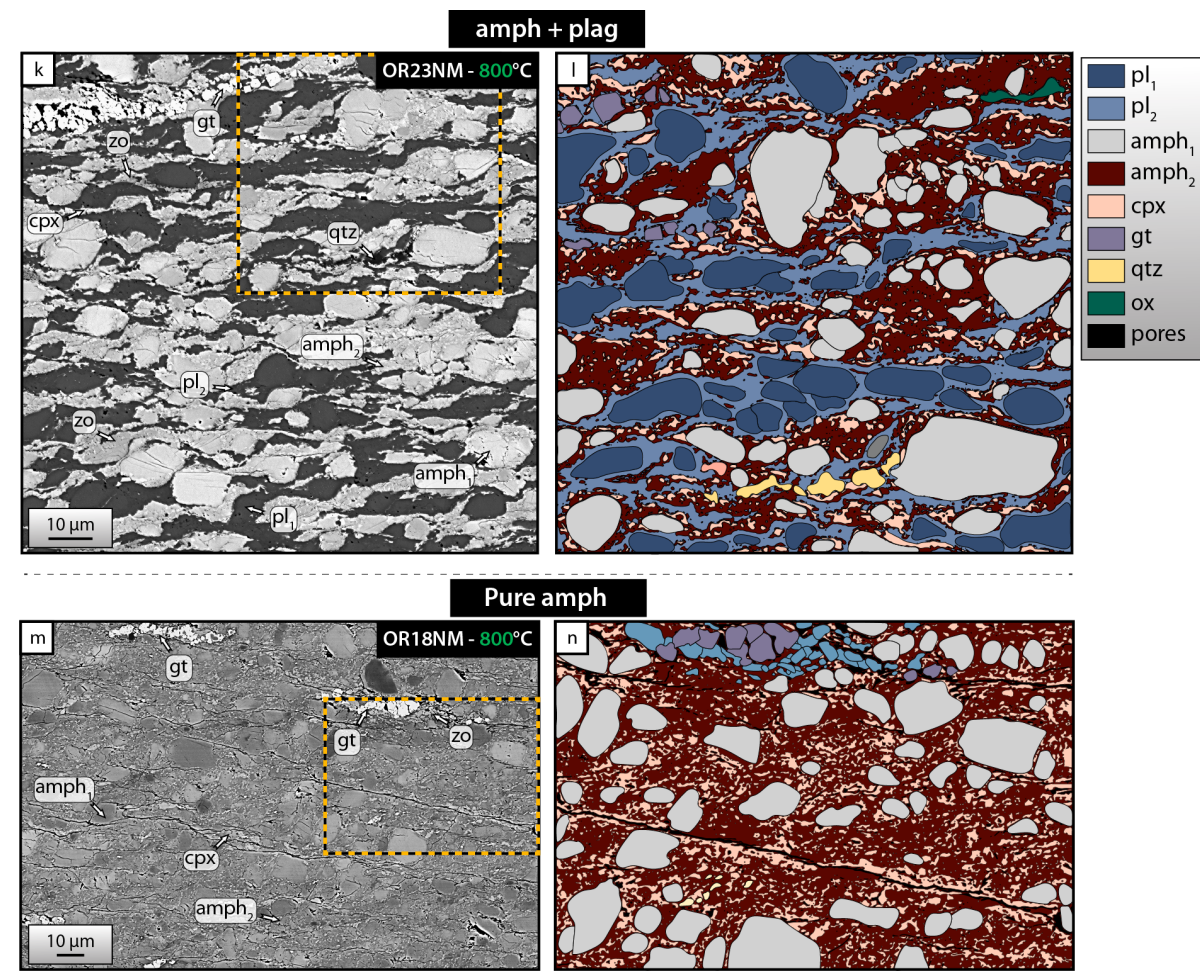

Figure 5. SEM BSE images representative of the different small-scale microstructures encountered in the assemblages and their respective manually digitized phase maps. Please note that the resolution is too low to resolve the full extent of phase mixing. opx: orthopyroxene, cpx: clinopyroxene, pl: plagioclase, amph: amphibole, qtz: quartz, gt: garnet, zo: zoisite.

\subsection{OH content and thermodynamic modeling}

Fe-rich opx and plag grains from Hidaka granulite show a broad and asymmetric infrared (IR) water absorption, with a maximum amplitude at $\sim 3580-3590 \mathrm{~cm}^{-1}$ (Fig. 9). The average $\mathrm{H}_{2} \mathrm{O}$ contents (ppm $\mathrm{H}_{2} \mathrm{O}$ by weight), calculated between 3750 and $3000 \mathrm{~cm}^{-1}$, are $451 \pm 35 \mathrm{ppm}$ for Fe-rich opx and $226 \pm 24$ ppm for plag. In contrast, there are no $\mathrm{H}_{2} \mathrm{O}$ IR absorption bands for Mg-rich opx grains from Damaping peridotite and plag grains from Sonora (Fig. 9).

Pseudo-sections for the Mg-rich opx + plag and Fe-rich opx + plag assemblages were calculated for different $\mathrm{H}_{2} \mathrm{O}$ contents in the simplified but representative system of our experiments $\left(\mathrm{Na}_{2} \mathrm{O}-\mathrm{CaO}-\mathrm{FeO}-\mathrm{MgO}-\mathrm{Al}_{2} \mathrm{O} 3-\mathrm{SiO}_{2}-\mathrm{H}_{2} \mathrm{O}\right)$ using the Perple_X 6.6.8 package (Connolly, 2009) combined with the updated database of Holland and Powell (1998) and the following solution model: amphibole (Dale et al., 2005), orthopyroxene (Powell and Holland, 1999), garnet, clinopyroxene (Holland and Powell, 1998), and feldspar (Newton et al., 1980).

At the experimental $P-T$ conditions, plag, opx, amph, qtz, cpx, and grt are expected to be stable phases in the Fe-rich opx + plag assemblage; plag, opx, amph, and qtz are expected to be stable phases in the Mg-rich opx + plag assemblage. The modeling of the Fe-rich opx + plag assemblage agrees rather well with the observed reaction product assem- blage, whereas the modeling of the Mg-rich opx + plag assemblage does not match the observed reaction product assemblage.

\subsection{Initial shear localization}

In the Mg-rich opx assemblages, shear deformation is initially localized between the boundaries of original opx 1 and $\operatorname{plag}_{1}$, where the nucleation of fine-grained tails of mixed phases that define the general shear foliation occurs (Fig. 10a). Everywhere, the new grains of opx 2 are pervasively mixed with plag $_{2}$ and amph grains (Fig. 10a). In contrast, the initial strain localization in the Fe-rich opx + plag assemblages predominantly forms amph + less $\mathrm{opx}_{2}$ shear bands or tails extending from opx 1 porphyroclasts. Amph $+\mathrm{opx}_{2}$ nucleates at boundaries between $\mathrm{opx}_{1}$ and plag, preferentially at extensional ends of $\mathrm{opx}_{1}$ grains, defining $\sigma$-type tails that stay connected to the original $\mathrm{opx}_{1}$ grains (Figs. 6b, 10b). In the samples of amph + plag starting material, the reaction products $\mathrm{cpx}+\mathrm{amph}_{2}+\operatorname{plag}_{2}+$ zo nucleate at the boundaries between original $\mathrm{amph}_{1}$ and plag $_{1}$ grains (Figs. 8a-c, 10c). $\mathrm{Amph}_{2}+\mathrm{cpx}$ tends to form mixed layers that surround and stay connected to $\mathrm{amph}_{1}$ porphyroclasts (Figs. 7a, b, 10c), while plag $_{2}+$ zo forms separate aggregates that tend to surround the $\mathrm{amp}_{2}+\mathrm{cpx}$ aggregates (Figs. 8c, 10c). Both types of reaction products or- 

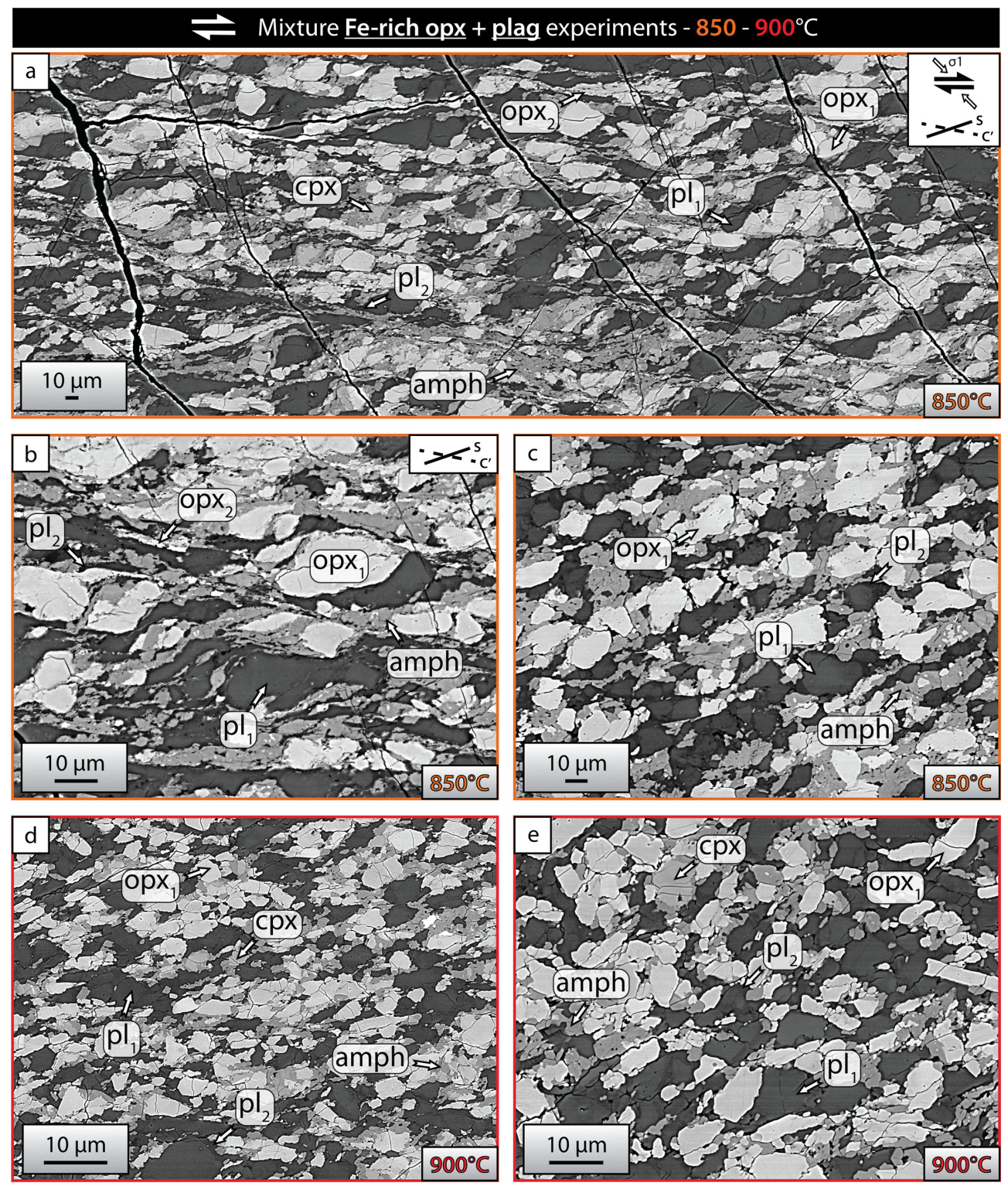

Figure 6. SEM BSE images representative of microstructures documented in deformed Fe-rich opx + plag assemblages. Amph and plag 2 are the main reaction products. At $850^{\circ} \mathrm{C}$, the deformation is heterogeneously distributed, and a strain gradient is clearly apparent at sample scale. (a-b) In strongly deformed parts, the amph appears as partially connected shear bands, while in the other parts (c) it appears as thick coronas around the opx 1 and plag 1 clasts. (e-f) At $900^{\circ} \mathrm{C}$, the deformation is more homogeneously distributed, and the reaction products appear as reaction coronas. opx: orthopyroxene, cpx: clinopyroxene, pl: plagioclase, amph: amphibole.

ganize into an anastomosing network of thin $\operatorname{amph}_{2}+\mathrm{cpx}$ and plag $_{2}+$ zo in which layers become progressively more parallel to the shear plane (Fig. 10c).

To summarize, two types of reaction products and related microstructures form in the two different starting material assemblages: (1) in the Mg-rich opx + plag samples, finegrained phase mixtures are produced by nucleation of reaction products and localize into more or less contiguous bands approximately parallel to the forcing block interface, i.e., the shear plane. (2) In the Fe-rich opx + plag and amph + plag samples, predominantly amph $+\mathrm{opx}_{2}$ and $\operatorname{plag}_{2}+$ zo shear bands and tails develop from opx $x_{1}$ porphyroclasts and stay connected with these. While fine-grained reaction products in case (1) produce C-type shear bands, the sample fabrics of case (2) develop S-C'-type shear band geometries in strongly deformed areas, the $\mathrm{C}^{\prime}$ bands of which are predominantly formed amph and plag $_{2}$. 

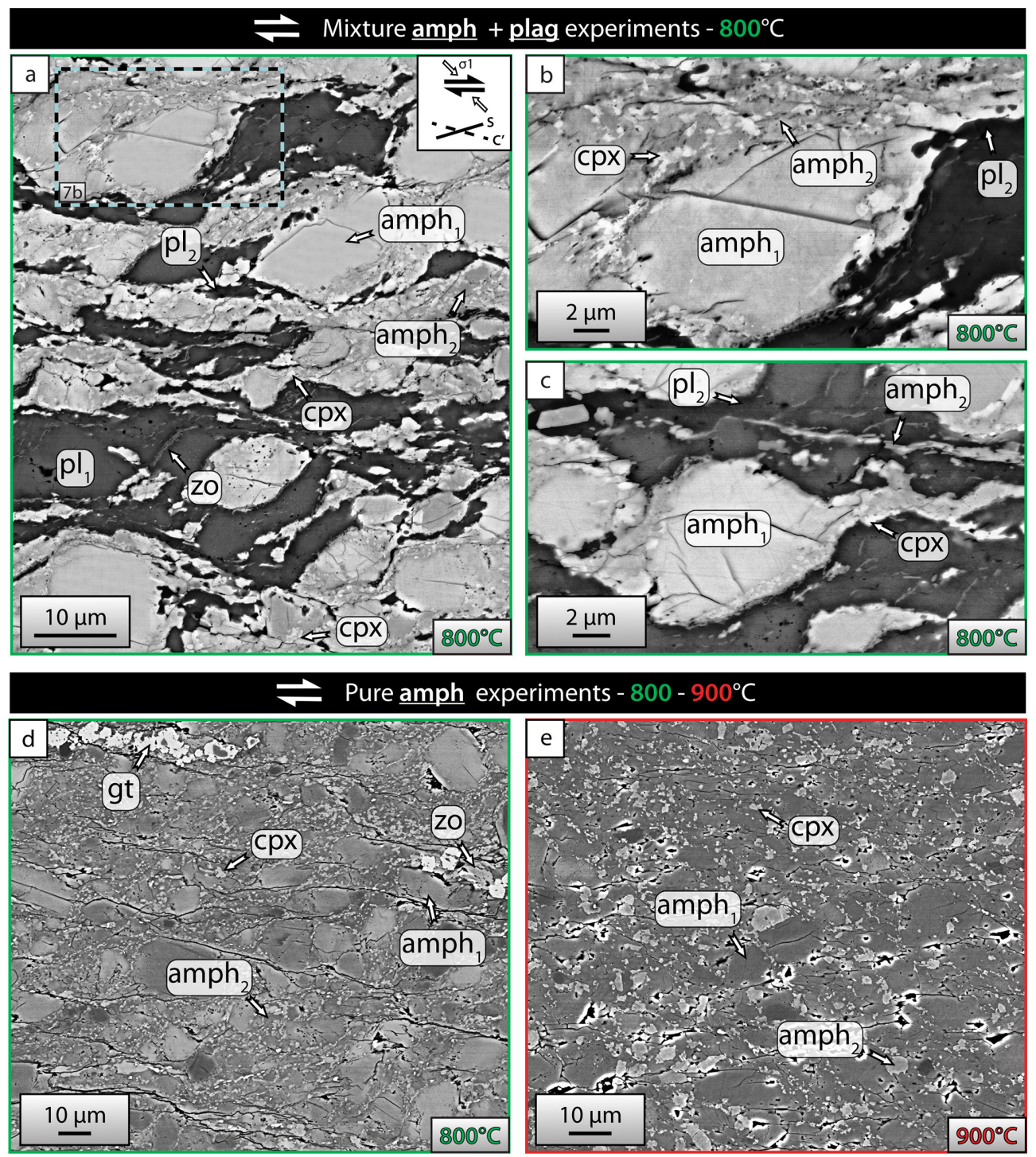

Figure 7. SEM BSE images representative of microstructures shown in deformed amph + plag and pure amph assemblages. (a, b, c) Nucleation of amph-rich layers in the amph + plag assemblage deformed at $800^{\circ} \mathrm{C}$. (d-e) The pure amph assemblages deformed at 800 and $900^{\circ} \mathrm{C}$ show the development of fine-grained mixture zones of amph 2 and cpx. opx: orthopyroxene, cpx: clinopyroxene, pl: plagioclase, amph: amphibole, gt: garnet, zo: zoisite.

\subsection{Abundance and grain size of reaction products}

The transition from low-strain to high-strain zones in the Mg-rich opx + plag assemblages is accompanied by a significant grain size reduction (mode of the distribution as the dominant grain size) from $\sim 15 \mu \mathrm{m}$ to $\sim 0.2 \mu \mathrm{m}$ (Fig. 11a). The high-strain zones concentrate most of the reconstituted material with roughly $\sim 65 \%$ and locally more than $\sim 80 \%$ of reaction products. This proportion is substantially higher compared to that in the low-strain zones $(\sim 25 \%)$, where no mixed-phase layers develop. Similarly, in the mixed-phase reacted zones of the original pure amph assemblages, the new grains are very small $(\sim 0.6 \mu \mathrm{m})$ and they represent nearly $\sim 61 \%$ of the assemblage (Fig. 11b). The amph grain size is also reduced in Fe-rich opx + plag assemblages compared to the starting material (Fig. 11c), but the reaction products are not as pervasively mixed and show a grain size that is approximately 1 order of magnitude larger $(1.9 \mu \mathrm{m})$ than that in the $\mathrm{Mg}$-rich opx + plag samples $(0.2 \mu \mathrm{m}$; Fig. $11 \mathrm{a})$. In the $850^{\circ} \mathrm{C}$ sample, the reaction products are largely connected to $\mathrm{opx}_{1}$ porphyroclasts, and their proportion increases with increasing proximity to higher-strained portions of the shear zone $(\sim 26 \%)$. In these Fe-rich opx + plag assemblages, amph is the main reaction product $(\sim 17 \%)$. In contrast, the quantity of reaction products at $900^{\circ} \mathrm{C}$ remains roughly constant at approximately $\sim 29 \%$ and there is no strain gradient. Fi- 


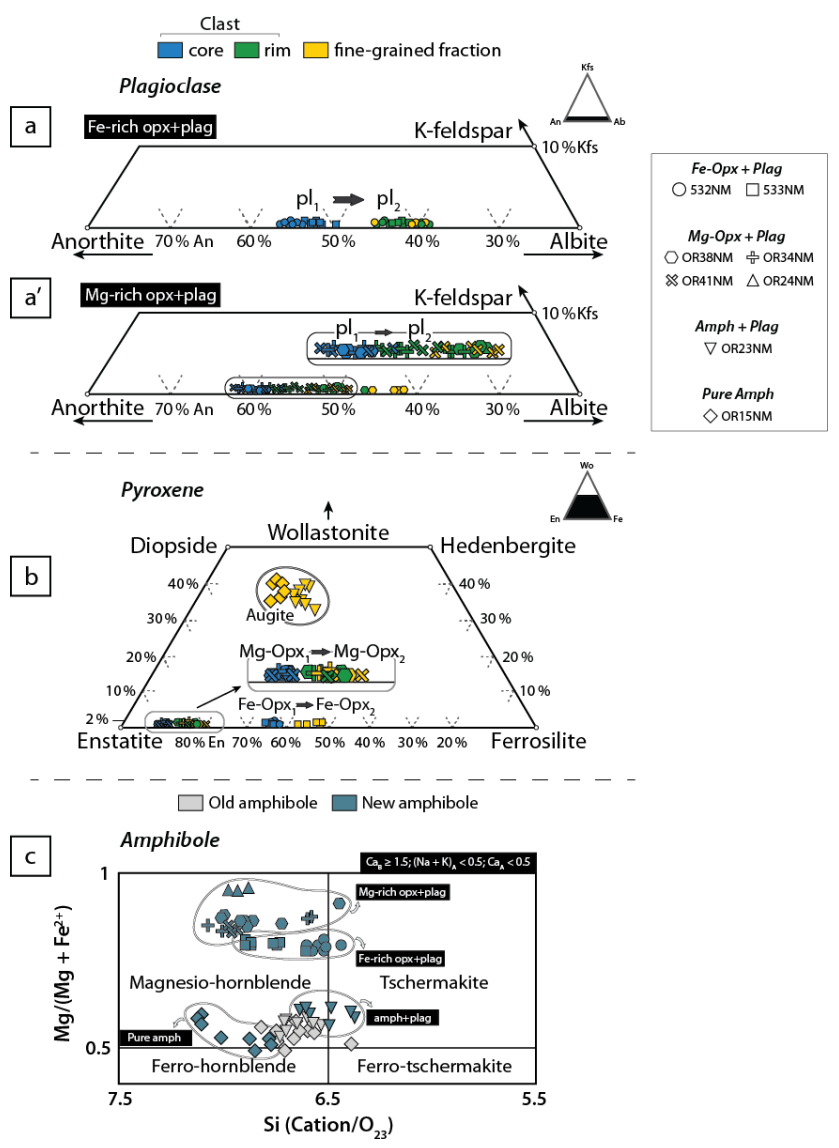

Figure 8. Mineral composition plots. Plagioclase compositions in the Fe-rich opx + plag (a) and Mg-rich opx + plag (b) assemblages plotted on the ternary diagram of orthoclase $\left(\mathrm{KAlSi}_{3} \mathrm{O}_{8}\right)$, albite $\left(\mathrm{NaAlSi}_{3} \mathrm{O}_{8}\right)$, and anorthite $\left(\mathrm{CaAlSi}_{3} \mathrm{O}_{8}\right)$. (c) Pyroxene compositions plotted on the ternary diagram of wollastonite $\left(\mathrm{Ca}_{2} \mathrm{Si}_{2} \mathrm{O}_{6}\right)$, enstatite $\left(\mathrm{Mg}_{2} \mathrm{Si}_{2} \mathrm{O}_{6}\right)$, and ferrosilite $\left(\mathrm{Fe}_{2} \mathrm{Si}_{2} \mathrm{O}_{6}\right)$. The chemical composition of plagioclase and pyroxene is divided into three subsets: clast core, clast rim, and fine grains. (d) Classification of amphibole in a graph of $\mathrm{Mg} /\left(\mathrm{Mg}+\mathrm{Fe}^{2+}\right)$ versus $\mathrm{Si}$ content for the case of $\mathrm{Ca} \geq 1.5,(\mathrm{Na}+\mathrm{K})_{\mathrm{A}}<0.5$, and $\mathrm{Ca}_{\mathrm{A}}<0.5$.

nally, in the amph + plag starting material, the nucleation in amph-rich shear bands is more extensive $(\sim 36 \%)$ and the grain size of cpx reaction products decreases to $\sim 1.3 \mu \mathrm{m}$ (Fig. 11d).

\subsection{Analysis of SPO and amphibole LPO}

Amph formed during deformation of Fe-rich opx + plag assemblages exhibits a distinct SPO oriented at $\sim 30^{\circ}$ to the shear direction (Fig. 12a-b). These amph aggregates occur as reaction rims around original $\mathrm{opx}_{1}$ grains and form in strongly deformed areas partly interconnected to aggregates that define $S-C$ ' fabrics (Fig. 12c). Plag $_{2}$ and opx 2 also reveal a well-defined SPO similarly oriented to amph. The preferred orientation of amph forms an angle of $\sim 30^{\circ}$ with the shear plane, slightly greater than that of plagioclase and original opx (Fig. 12a-b). In addition, the amph reaction seams in high-stress sites of opx porphyroclasts are significantly thinner compared to those in low-stress or extensional sites, indicating that amph grows preferentially in strain shadows. In the higher-strained portions of the shear zone deformed at $850^{\circ} \mathrm{C}$, the foliation defined by amph-dominated layers rotates and is now well-oriented subparallel to the boundaries of C' shear bands or the shear plane (Fig. 12c). Within these shear bands, amph grains show a moderate LPO with [001] axes aligned subparallel to the boundaries of C' shear bands and poles (100) normal to the shear plane (Fig. 12c-d). In the mixed zones of Mg-rich opx + plag samples, the fine grains are characterized by equant grain shapes with an aspect ratio of 1.23 (Fig. 13) and a weak preferred orientation either parallel or at $45^{\circ}$ to the shear plane (Fig. 13).

\section{Discussion}

\subsection{Nucleation, grain size reduction, and phase mixing}

In this study, the deformation of two-phase assemblages is accompanied by the nucleation of new grains with (1) systematic differences in composition between new grains and parent grains (Fig. 8), (2) significant grain size reduction (Fig. 11), and (3) a new spatial arrangement of reaction products into fine-grained mixture zones (Fig. 5). Based on these observations, we infer that grain size reduction and phase mixing both result from the nucleation of new phases (e.g., Kruse and Stünitz, 1999; Kenkmann and Dresen, 2002; Kilian et al., 2011; Linckens et al., 2015; Platt, 2015; Précigout and Stünitz, 2016; Mansard et al., 2018). Despite common features, our samples have developed two sets of microstructures distinguished mainly by the size and spatial arrangement of reaction products and the degree of phase mixing. We discuss these differences below.

In the Mg-rich opx + plag assemblages, a strain gradient is clearly observed and expressed by the development of low- and high-strain zones (Figs. 3a, 4). This is particularly notable in the sample deformed at $850{ }^{\circ} \mathrm{C}$. The transition from a low- to high-strain zone is accompanied by drastic grain size reduction and an increase in reaction products within localized mixed zones by a factor of more than 2 (Fig. 11a). The grain size of reaction products in the mixed high-strain zones $(\sim 0.2 \mu \mathrm{m})$ is about 2 orders of magnitude smaller than the opx grain size of the starting material and the low-strain regions $(\sim 10-20 \mu \mathrm{m}$; Fig. 11a). Similarly, an extensive nucleation of reaction products within mixedphase zones is documented in the pure amph starting material (Fig. 7d-e). The reaction products are also very small, far below $1 \mu \mathrm{m}(\sim 0.6 \mu \mathrm{m}$; Fig. 11b). As documented in Mansard et al. (2020), such a correlation between deformation, mineral reactions, and related grain size reduction in Mg-rich assemblages has been also observed in experimentally deformed fine-grained gneiss (Holyoke and Tullis, 2006a, b), 

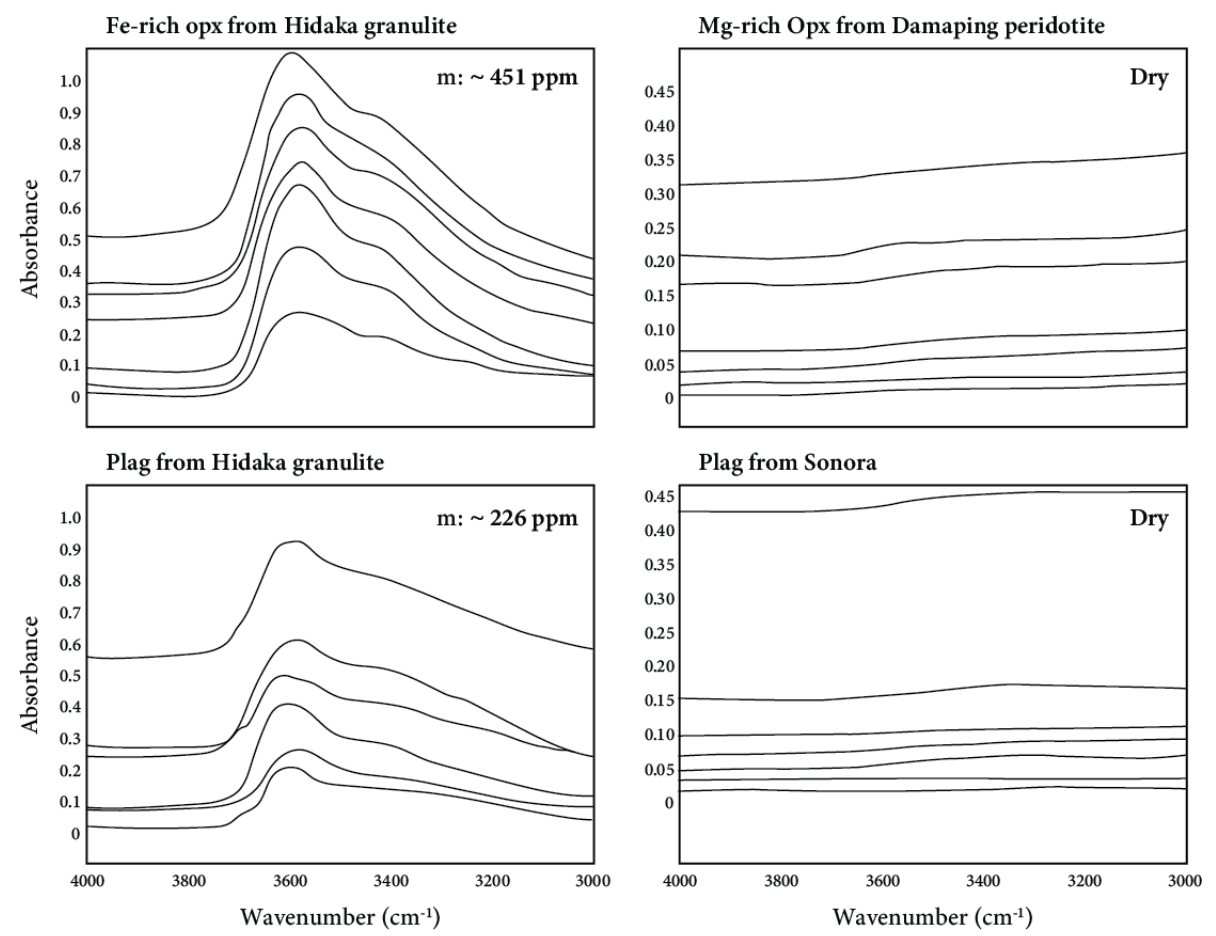

Figure 9. Representative Fourier transform infrared (FTIR) spectra of orthopyroxene and plagioclase starting materials. m: average water content.

plagioclase + olivine samples (De Ronde et al., 2005; De Ronde and Stünitz, 2007), and plagioclase + pyroxene samples (Marti et al., 2018).

In the Fe-rich opx + plag assemblages, amph is by far the more abundant product, and there is less phase mixing (Fig. $5 \mathrm{~g}-\mathrm{j}$ ). The reaction products consist mainly of thick rims around the opx 1 (Fig. 6c) or amph-dominated tails and shear bands (Fig. 6a-b). The abundance of reaction products increases with increasing proximity to strongly deformed portions of the shear zone. The reaction products have a grain size about 1 order of magnitude smaller than the starting material $(\sim 1.9 \mu \mathrm{m})$ but 1 order of magnitude larger than the mixed reaction products in the Mg-rich opx + plag assemblages (Fig. 11). Similarly to the Fe-rich opx + plag assemblages, amph-rich shear bands have developed in the amph + plag assemblages (Fig. 7a-c), and the grain size, reduced by about 1 order of magnitude compared to the starting material, is 1 order of magnitude larger than in the mixed zones in the Mg-rich opx + plag assemblages (Fig. 11).

Two types of major microstructures can be distinguished: (1) in one case, intense grain size reduction by 2 orders of magnitude is produced by nucleation of reaction products in pervasive and layered phase mixtures (Mg-rich opx + plag and pure amph starting materials); (2) in the other case, the reaction products are less pervasively mixed and develop aggregates that are dominated by amph extending from opx porphyroclasts. These aggregates have a grain size 1 order of magnitude larger than (1) and may form C' shear bands or tails connected to opx porphyroclasts.

\subsection{Deformation processes}

As the reaction products in $\mathrm{Mg}$-rich opx + plag samples occur in pervasively mixed high-strain zones and layers with equant grains of a size far below $1 \mu \mathrm{m}$, the dominant deformation mechanism is inferred to be one of grain-sizesensitive creep. The absence of well-developed layering of separate phases and absence of strong elongation of individual grains during GSS creep suggest that grain boundary sliding makes the dominant kinematic contribution to the finite strain (Rachinger sliding; e.g., Langdon, 2006). Such a deformation mechanism should probably be termed diffusionaccommodated grain boundary sliding (GBS) or, more generally, as a fluid has been present and solution precipitation is the probable transfer mechanism, dissolution-precipitation creep (DPC). The pronounced weakening of the samples in combination with localization of strain made strain rate stepping tests problematic in our samples, so the deformation mechanism is primarily identified based on microstructures. At first, the microstructures are similar to other cases in which such deformation mechanisms have been identified (e.g., Marti et al., 2017, 2018; De Ronde et al., 2005; Stünitz and Tullis, 2001; Holyoke and Tullis, 2006a, b; Tasaka et al., 2016, 2017; Getsinger and Hirth, 2014). The transition from low- to high-strain zones in the Mg-rich opx + plag as- 

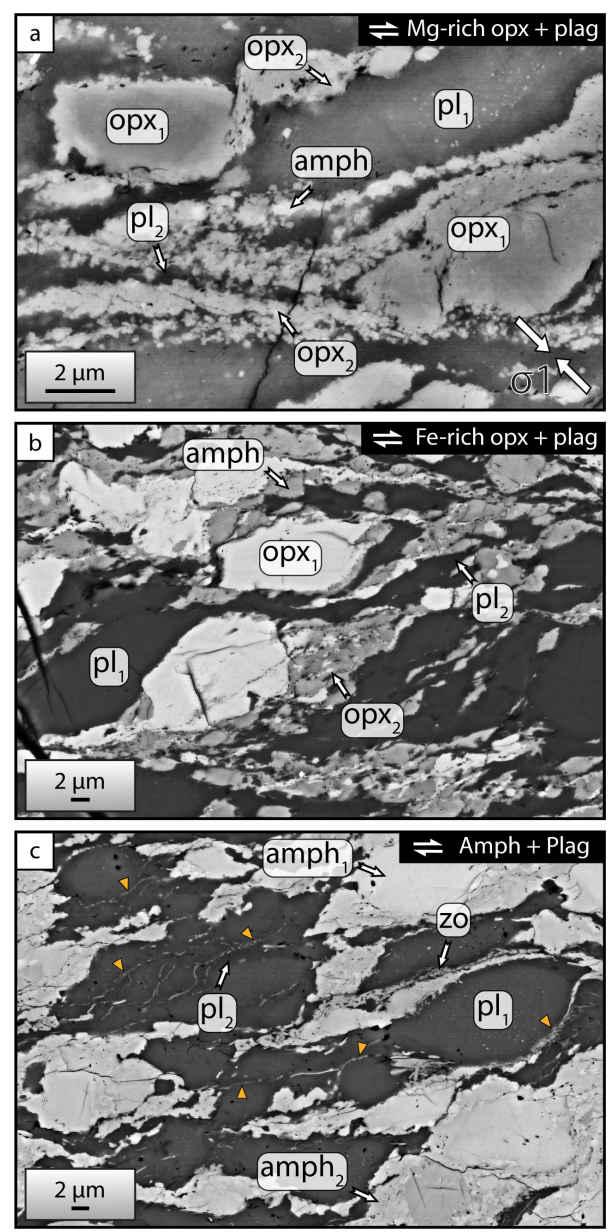

Figure 10. SEM BSE images of incipient nucleation and shear localization. (a) In the Mg-rich opx + plag assemblages, fine-grained tails of mixed phases nucleate at the edges of original grains. In the Fe-rich opx + plag (b) and amph + plag (c) assemblages, the nucleation is fairly monophase. The new grains tend to organize into an anastomosing network of thin amphibole and zoisite (orange triangle). opx: orthopyroxene, pl: plagioclase, amph: amphibole, zo: zoisite.

semblages marks the transition from a two-phase aggregate with strong phases (starting material) potentially deforming by dislocation creep to a material deforming by grainsize-sensitive mechanisms, including DPC and/or GBS (e.g., Boullier and Gueguen, 1975; Kerrich et al., 1980; Schmid, 1982; Brodie and Rutter, 1987; Kilian et al., 2011), whereby samples deform by low bulk stresses (Fig. 2).

The spatial arrangement of mineral phases in mixed aggregates by nucleation impedes grain growth (e.g., Olgaard and Evans, 1986, 1988). As documented by Mansard et al. (2020), the mixing of mineral phases is homogeneous and starts from peak stress, in favor of GBS accommodated by DPC (e.g., Fliervoet et al., 1997; Kilian et al., 2011; Linckens et al., 2011, 2015). The original plag 1 almost completely disappeared in the high-strain zones of Mg-rich samples, while the original $\mathrm{opx}_{1}$ remains as small clasts embedded in finegrained mixed zones (Figs. 3a, 4a-c). Although the opx $x_{1}$ is still present, its proportion, aspect ratio, and size decrease compared to that in the low-strain zones (Fig. 4). These microstructures suggest that $\mathrm{opx}_{1}$ grains act as rigid particles affected by dissolution and, together with plag 1 , represent a source of elements required for the development of the ductile fine-grained zone deformed by diffusion-accommodated GBS.

In the Fe-rich opx + plag samples, the deformation mechanism is also assumed to be predominantly DPC, as demonstrated by the fact that (1) the samples deform at lower stresses well below the Goetze criterion, and (2) the microstructures that consist of elongate mineral aggregates of reaction products dominantly grow in the extension direction, shear bands, or dilatant sites (Figs. 2, 6, 12). The nucleation of reaction products, anisotropic growth, and local dilatancy could also require the operation of GBS (Lifshitz sliding; Paterson, 1990; Langdon, 2006). The grain sizes of the reaction products in the Fe-rich opx + plag samples are larger, resulting in higher flow stresses compared to the final stresses - after weakening - of the Mg-rich opx + plag samples (Figs. 2, 11; e.g., Mansard et al., 2020).

In addition, the amphibole fabric displays a fairly moderate but consistent LPO with [001] axes aligned subparallel to the boundaries of C' shear bands (Fig. 12). This type of LPO is typical for naturally deformed amphibole (e.g., Berger and Stünitz, 1996). It is generally accepted that significant LPO of minerals is attributed to viscous deformation dominated by dislocation creep (e.g., Nicolas and Christensen, 1987; Knipe, 1989; Wenk and Christie, 1991). However, an increasing number of studies have found that LPOs can develop without the dominance of dislocation creep, as shown in olivine (e.g., Sundberg and Cooper, 2008; Miyazaki et al., 2013, Précigout and Hirth, 2014), plagioclase (e.g., Barreiro et al., 2007), and amphibole (e.g., Getsinger and Hirth, 2014). The amph LPOs presented here are similar to the ones documented in experimentally deformed amphibolite by Getsinger and Hirth (2014) and to those of natural samples deformed at lower crustal conditions (e.g., Berger and Stünitz, 1996; Getsinger et al., 2013; Menegon et al., 2015; Okudaira et al., 2015). These studies have demonstrated that oriented grain growth of pyroxenes and amphibole can lead to consistent amphibole-pyroxene LPO, even though diffusion creep is the dominant deformation mechanism. We thus interpret the presence of amphibole LPO in our samples as resulting from oriented growth with the fastest growth direction ( $c$ axis) in the flow direction. This supports an important contribution of metamorphic re-equilibration, chemical transport, and hence DPC in the development of amph mylonitic foliation in the Fe-rich and amph + plag assemblages (e.g., Bons and Den Brok, 2000; Berger and Stünitz, 1996). 

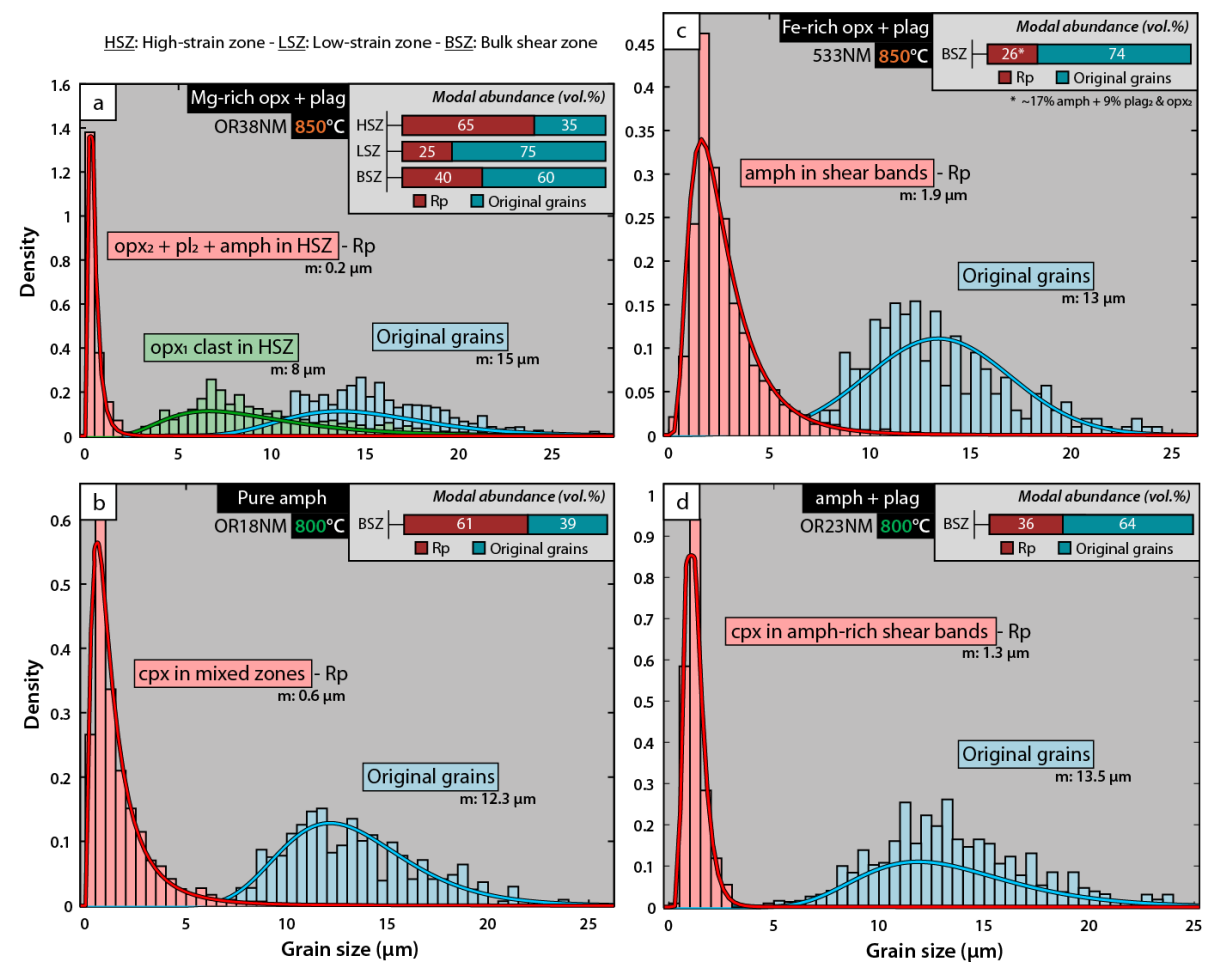

Figure 11. Grain size distribution reported as a histogram of grain size versus density for different category of grains in the Mg-rich opx + plag (a), pure amph (b), Fe-rich opx + plag (c), and amph + plag (d) assemblages. Overall, there is a significant and systematic reduction in grain size between the original grains and the reaction products. The lognormal distribution curves are fit for each grain size distribution. The modal proportion (vol. \%) of reaction products and original grains of each assemblage is also reported.

\subsection{Formation of polyphase vs. monophase shear bands and implications for the degree of rheological weakening}

\subsubsection{Polyphase shear bands}

In $\mathrm{Mg}$-rich opx + plag assemblages at $850^{\circ} \mathrm{C}$, the mixture zones are strongly connected to form a single high-strain zone that traverses the sample through the center from one interface of the forcing block to the other (Fig. 3). The deformation microstructures at early stages of our experiments suggest that phase mixing occurs at phase boundaries with the nucleation of small equant grains in polyphase aggregates and layers (Fig. 10a). These polyphase aggregates, into which strain is partitioned, are composed of opx $2, \operatorname{plag}_{2}$, and amph. It has been documented by many authors (e.g., Kruse and Stünitz, 1999; Kenkmann and Dresen, 2002; Linckens et al., 2015) that phase mixing can be produced by the nucleation of new phases within clast tails. The effect of mixing on grain size is significant as grain growth is impeded by the nucleation of second phases and preserves a small grain size in the mixture zones (Fig. 11a), producing stable microstructures (e.g., Olgaard and Evans, 1986; 1988; Olgaard, 1990; Stünitz and Fitz Gerald, 1993; Herwegh and Berger, 2004; Warren and Hirth, 2006; Farla et al., 2013). The opening of cavities and the formation of dilatant sites in which material can nucleate (e.g., Fusseis et al., 2009; Platt, 2015; Menegon et al., 2015; Précigout and Stünitz, 2016; Précigout et al., 2017; Gilgannon et al., 2017) may be additional factors to promote mixing and lead to the stabilization of small grain sizes.

\subsubsection{Amphibole-dominated $\sigma$ tails and shear bands}

In the Fe-rich opx + plag samples, the majority of reaction products occurs in strongly deformed portions of the shear zones, indicating a close relationship between deformation and mineral reactions (Fig. 3b). These portions are not characterized by the development of intensely mixed zones with C-type mylonite geometries, as in the Mg-rich opx + plag assemblages. Instead, deformation and reaction have induced the formation of shear bands or, more frequently, $\sigma$ tails at the tip of elongated amph or amph $+\mathrm{opx}_{2}$ (Figs. 5, 6). These tails stay connected with the original porphyroclasts, forming $\mathrm{S}-\mathrm{C}$ or S-C' fabrics. Similarly, the amph + plag assemblage is banded and shows a subhorizontal mylonitic foliation characterized by the development of amph-rich shear bands (Fig. 3c). These shear bands have a similar geometry as those of the amph $+\mathrm{opx}_{2}$ bands and $\sigma$ clasts of the Fe-rich opx + plag assemblages. 

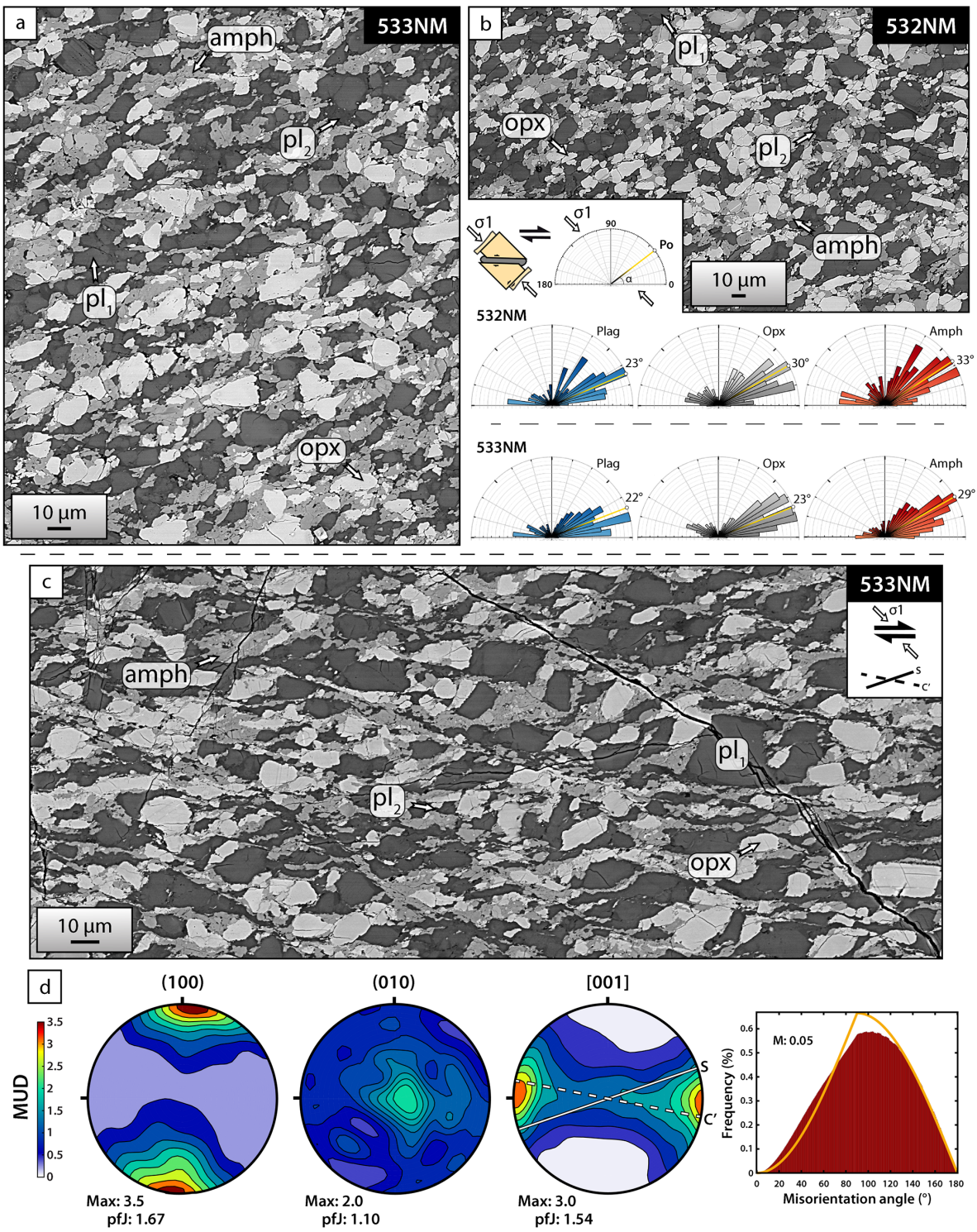

Figure 12. SPO and amph LPOs in the Fe-rich opx + plag assemblages. (a-b) Rose diagrams of the SPO of plag 1 , opx 1 , and amph (a: $533 \mathrm{NM}-850^{\circ} \mathrm{C}$, b: $532 \mathrm{NM}-900^{\circ} \mathrm{C}$ ). (c) Strongly deformed part of the Fe-rich opx + plag assemblage deformed at $850^{\circ} \mathrm{C}$. (d) Amph LPOs are shown for the (100) plane, (010) plane, and [001] axis with respect to the shear direction, considering one point per grain. Number of data points: 365 ; step size: $100 \mathrm{~nm}$; average grain size of amphibole: $4.1 \mu \mathrm{m}$. pfJ: pole figure texture index, MUD: multiple of uniform distribution, opx: orthopyroxene, pl: plagioclase, amph: amphibole.

\subsubsection{Effects of shear band interconnection on the degree of rheological weakening}

Shear bands connect differently depending on the composition of the starting material. In the Mg-rich opx + plag samples, strain tends to produce mixed and connected finegrained bands with C-type geometry in high-strain zones (Figs. 3a, 4, 10a, 11a). This gave rise to the development of a single throughgoing high-strain zone that probably contributed to strongly weakening the samples after peak stress (Figs. 2, 3a). And the samples are so weak that we con- sider the fine-grained aggregate of reaction products to be sustaining almost the whole sample strength. In contrast, the Fe-rich opx + plag and amph + plag mixtures tend to form clusters and only locally connected amph-rich $\sigma$ tails at porphyroclasts (S-C- or S-C'-type geometries; Figs. 3b-c, 5g1,6 , and $10 \mathrm{~b}$ ). When the shear bands and tails of clasts are only partially connected or nonconnected, there is no peak stress and hence no subsequent weakening (Fig. 3b; Fe-rich opx + plag assemblages). This feature may be caused by two aspects: (1) the absence of highly connected aggregates of reaction products and (2) the fact that reaction products have 


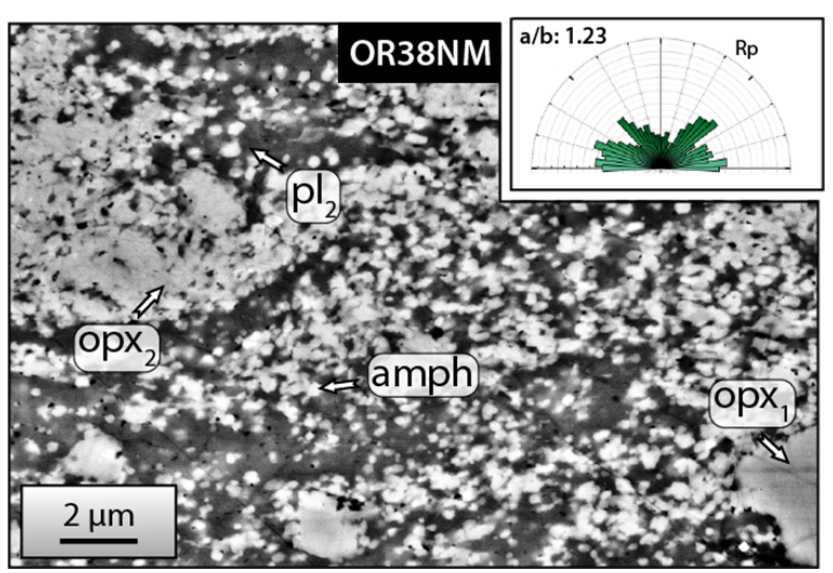

Figure 13. Rose diagram of the SPO of undifferentiated reaction products in fine-grained mixed zones in the Mg-rich opx + plag assemblages. opx: orthopyroxene, pl: plagioclase, amph: amphibole.

a larger grain size and are less intensely mixed so that GSS creep occurs at lower strain rate. The connectivity of the reaction products appears to also be affected by their geometry; the fine-grained C-type bands are parallel to the shear plane and seem to connect much more easily than the local S-Cand $\mathrm{S}-\mathrm{C}$ '-type tails and shear bands.

The fact that the connectivity of weak zones has a major effect on the bulk sample strength has been documented by, e.g., Pec et al. (2012a, b, 2016), Palazzin et al. (2018), and Richter et al. (2018) and is definitely a major rheological factor in these mafic samples. However, in addition to the connectivity, we also documented different microstructures in the weak parts of each sample, pointing to a difference in GBS-DPC mechanisms. The less intensely mixed layers, tails, and shear bands in the Fe-rich assemblages display higher aspect ratios of the reaction products, i.e., more fiber-like grains (Figs. 6c, 10b, 12a-b). These microstructures constitute a type of DPC that tends more towards grainscale DPC, whereby ideally (in the end-member case) the grain shapes would reflect the finite strain, and grain boundary sliding is more a type of Lifshitz sliding. We cannot consider the Fe-rich opx + plag samples to be representative of the end-member case, but they approach this situation far more than the fine-grained, well-mixed mylonitic bands of equant grains in Mg-rich opx + plag samples (Figs. 4ab, 13), wherein DPC is probably dominated by GBS or Rachinger sliding. The combination of relatively fast strain rates in the fine-grained layers and strong connectivity of the reaction product zones causes the pronounced weakening in the Mg-rich opx + plag samples, emphasizing the importance of grain size for material strength (Mansard et al., 2020). Such expected higher strain rates in aggregates dominated by Rachinger sliding have been pointed out by Paterson (1990).

\section{4 $\mathrm{OH}$ speciation and concentration in the starting material}

Our absorption spectra have been compared with reference spectra available for plagioclase (Johnson and Rossmann, 2003, 2004; Johnson, 2006) and orthopyroxene (Skogby, 2006) in the literature. While the IR spectra we obtained in plagioclase and opx are very similar to one another, they strongly differ from the reference spectra, which correspond to structural $\mathrm{OH}$ or $\mathrm{H}_{2} \mathrm{O}$, i.e., to molecules with specific position and orientation in the structure of the host mineral. The spectra in plagioclase bear the largest similarities to reference measurements of fluid inclusions and alteration products (Johnson and Rossman, 2004), i.e., $\mathrm{OH}$ or $\mathrm{H}_{2} \mathrm{O}$ molecules not structurally bound to the host solid. This interpretation is also favored by the very similar shape of the spectra in plag and opx (Fig. 9), whereas structural $\mathrm{OH}$ or $\mathrm{H}_{2} \mathrm{O}$ in these minerals yields different spectra.

According to this interpretation, the calibration coefficient for the $\mathrm{H}_{2} \mathrm{O}$ content should be different from that of the mineral-specific ones we have used. However, using the general coefficient from Paterson (1982) would not significantly affect the estimates of $\mathrm{H}_{2} \mathrm{O}$ concentration in the starting material: the integrated absorption coefficient used in Fig. 9 is $80600 \mathrm{~L} /\left(\mathrm{mol} \mathrm{H}_{2} \mathrm{O} \mathrm{cm}^{2}\right)$ for opx (Bell et al., 1995) and $107000 \mathrm{~L} /\left(\mathrm{mol} \mathrm{H}_{2} \mathrm{O} \mathrm{cm}^{2}\right)$ for plag, i.e., relatively similar to the estimate of $\left.82200 \mathrm{~L} /(\mathrm{mol} \mathrm{cm})^{2}\right)$ for quartz and other silicates (Paterson, 1982).

Bearing in mind these limitations, the amount of $\mathrm{H}_{2} \mathrm{O}$ initially present in the minerals of the Fe-rich system is of the order of $451 \mathrm{ppm}$ for pyroxene and $226 \mathrm{ppm}$ for plagioclase, whereas it is effectively zero in the Mg-rich system. The total amount of $\mathrm{H}_{2} \mathrm{O}$ in pyroxene and plagioclase in the Fe-rich system is $\sim 677 \mathrm{ppm}$, i.e., more than half with respect to the addition of $\mathrm{H}_{2} \mathrm{O}$ to the powder. The initial amount of $\mathrm{H}_{2} \mathrm{O}$ estimated by FTIR is a lower bound as only grain interiors were analyzed by FTIR, while crushed polycrystalline aggregates include grain boundary area with additional adsorbed $\mathrm{H}_{2} \mathrm{O}$ (Palazzin et al., 2018). In summary, it is estimated that the total amount of $\mathrm{H}_{2} \mathrm{O}$ in the Fe-rich system is $\sim 50 \%$ higher than that in the $\mathrm{Mg}$-rich system.

\subsection{Role of $\mathrm{H}_{2} \mathrm{O}$ availability in reaction}

In the Fe-rich opx + plag samples, a large amount of amph is formed with a minor amount of opx2, whereas in the $\mathrm{Mg}$ rich opx + plag samples, the nucleation of a new opx 2 is more abundant. The thermodynamic modeling of the Fe-rich opx + plag system has produced a result similar to that of Okudaira et al. (2015) as an extension to higher pressures and temperatures that is rather consistent with the observed phase compositions, although the predicted garnet was not observed, and cpx is of lower abundance than predicted by the model. However, it was not possible to model the observed reactions in the Mg-rich opx + plag system in terms of 
phase compositions. The reason for the inadequate modeling is most likely the somewhat inadequate activity-composition relation in the Mg-rich system. Due to this issue, it is impossible to calculate differences in free energy between the two systems as a possible explanation for the different reaction kinetics.

Another difference between the two starting materials is the higher content of $\mathrm{H}_{2} \mathrm{O}$ in the Fe-rich system. Considering that amphibole contains $2 \mathrm{wt}$. $\%$ of $\mathrm{H}_{2} \mathrm{O}$, the amount of $\mathrm{H}_{2} \mathrm{O}$ required to form $17 \%$ of amphibole would be $3400 \mathrm{wt}$. ppm, which is a bit higher than the total amount of $\mathrm{H}_{2} \mathrm{O}$ present in the sample. Our estimation of $17 \%$ amphibole content is also rough. In any case, it is probable that a large amount, if not all, of the $\mathrm{H}_{2} \mathrm{O}$ is used up by amphibole formation, even though the total amount of $\mathrm{H}_{2} \mathrm{O}$ in the Fe-rich system is greater to begin with. Conversely, the amount of amphibole formed in the $\mathrm{Mg}$-opx + plag assemblage is subordinate so that, despite a lower total amount of $\mathrm{H}_{2} \mathrm{O}$ in the starting material, there is probably free $\mathrm{H}_{2} \mathrm{O}$ present in the $\mathrm{Mg}$-rich system. It could be speculated that the presence of more $\mathrm{H}_{2} \mathrm{O}$ in the grain boundary region could lead to a more disperse nucleation of reaction products in the Mg-rich system.

\subsection{Influence of reaction on material strength}

\subsubsection{Behavior at the onset of deformation: peak strength}

Considering that the rheological behavior is strongly controlled by the reaction products, it is inferred that the Ferich opx + plag assemblages do not develop a peak stress behavior and initially deform at lower stresses than the $\mathrm{Mg}$ rich opx + plag assemblages because in the Fe-rich assemblages reaction products nucleate faster than in the Mg-rich assemblages at early stages of the experiment (Figs. 2b-d, 14). We do not have samples of the same low strain for Mgrich and Fe-rich compositions, but OR61 and 557NM (Fig. 2) can be compared as approximately similar strain samples. The Mg-rich material shows a slightly lower initial quantity of reaction products. The faster nucleation of reaction products in Fe-rich samples is consistent with the recent study of Mansard et al. (2020), showing that for samples wherein reaction products nucleate at an early stage with respect to the onset of deformation, the peak strength is lowered. The system that reacts faster is the Fe-rich one, which contains a greater concentration of $\mathrm{H}_{2} \mathrm{O}$. This water is present inside the grains of the starting material, whereas the added water is located along the grain boundaries. These differences suggest that the presence of $\mathrm{H}_{2} \mathrm{O}$ in inclusions or aggregates inside grains may have triggered the onset of hydration reactions so that, possibly, the higher initial content in $\mathrm{H}_{2} \mathrm{O}$ and its location inside grains in the Fe-rich system may have had a positive effect on the kinetics of reaction. Microcracking is common in opx grains, so $\mathrm{H}_{2} \mathrm{O}$ initially stored in the grains may easily become available for reactions during de- formation, as observed in Palazzin et al. (2018). The reactions commenced earlier in the Fe-rich system, presenting a weakening agent in the early stages of the deformation. The fact that sample strength is directly related to $\mathrm{H}_{2} \mathrm{O}$ content, such as in $\mathrm{H}_{2} \mathrm{O}$ weakening in olivine and quartz, is very unlikely because crystal plasticity does not contribute significantly as a deformation mechanism.

\subsubsection{Behavior at large strain}

During later stages of our experiments, the highest proportion of reaction products and the smallest grain size are documented for the Mg-rich opx + plag samples (Figs. 11, 14), which also record a far more pronounced weakening with respect to the Fe-rich samples (Figs. 2, 14). The phase mixing and fine grain sizes of the reaction products in Mg-rich opx + plag samples cause greater strain partitioning and suggest a faster nucleation rate after peak stress, even though the Fe-rich opx + plag samples react faster at early stages of experiment (Figs. 8, 14). Deformation and reaction products are strongly localized and connected in high-strain zones of the Mg-rich opx + plag assemblages (Figs. 3a, 10a), whereas the reaction products in the Fe-rich opx + plag samples are poorly connected or nonconnected (Figs. 3b, 10b). In the case in which the viscosity of the reaction products is very low (fine-grained mixture zones in the Mg-rich opx + plag) compared to the starting material, the reacting domains tend to connect much better during the deformation (Fig. 14). It has been demonstrated that deformation enhances the kinetics of mineral reactions (De Ronde and Stünitz, 2007; Mansard et al., 2020) so that the significant localization of deformation in the Mg-rich opx + plag samples may account for the more advanced reaction progress in those samples. In contrast, if the reaction products are stiffer - in Fe-rich opx + plag samples, amphibole appears to be one of the strongest silicates (Brodie and Rutter, 1985; Berger and Stünitz, 1996) - or harden during the reaction (see Fe-rich opx + plag at $900^{\circ} \mathrm{C}$; Fig. 2d), the feedback effect of enhancing reaction kinetics appears to be limited and no weakening is observed (Fig. 2). Therefore, the viscosity of the Fe-rich opx + plag and amph + plag assemblages is related to their ability to transform and connect.

The reason why the reaction products in $\mathrm{Mg}$-rich samples characterized by fine-grained layers that do not stay attached to the original opx $x_{1}$ clasts is not clear yet, but this might be related to the difference in the amount and distribution of $\mathrm{H}_{2} \mathrm{O}$. Indeed, in the Fe-rich system, the reaction products are dominated by a single-phase material, i.e., amphibole (Fig. 6). In contrast, although the very small grain size did not allow for any quantitative estimates of the $\mathrm{Mg}$-rich reaction products, much more phase mixing occurs in the latter. The difference in the nature and proportion of reaction products between Fe- and $\mathrm{Mg}$-rich systems is a major control factor for their later resistance evolution during connectivity and reaction progress. This situation illustrates that substantially 

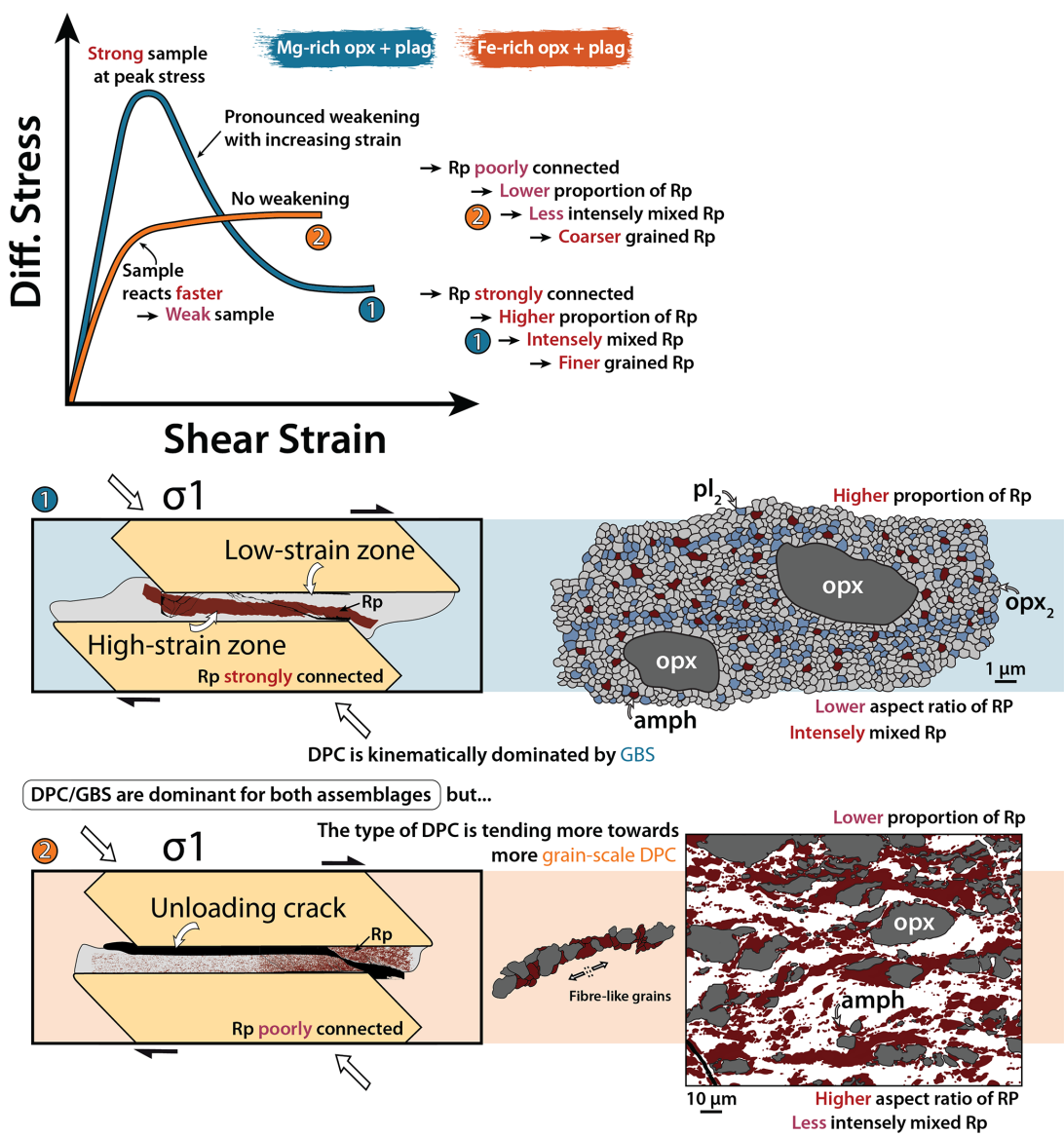

Figure 14. Schematic mechanical and microstructural evolution of the deformed Mg-rich opx + plag and Fe-rich opx + plag assemblages. Rp: reaction product, opx: orthopyroxene, pl: plagioclase, amph: amphibole.

more work is needed to understand the relationship between mineral reaction and mechanical behavior.

\subsection{Geological application}

According to the results of this study, the rheological behavior of two-phase mixtures of mafic composition is dependent on mineral reactions, as reactions can trigger strain localization and weakening, even at low shear strain. In two different starting materials, the reactions coupled with dissolutionprecipitation creep (DPC) in combination with grain boundary sliding allow the mafic assemblage to be deformed. Without mineral reactions, the mafic assemblage of pyroxene and plagioclase would be too strong to be deformed by dislocation creep at the applied strain rates (Mansard et al., 2020). This situation is the same in naturally deformed rocks: below $\sim 700^{\circ} \mathrm{C}$, pyroxene and plagioclase assemblages do not show significant crystal plastic deformation (e.g., Brodie and Rutter, 1985, 1992). The partly extensive deformation of mafic rocks at lower or higher metamorphic grades appears to be dependent on mineral reactions, which can induce the development of rheologically weaker phases, on the formation of fine-grained aggregates deforming by GSS creep, or on both (e.g., Brodie and Rutter, 1985; Brodie et al., 1992; Handy and Stünitz, 2002; Brander et al., 2012; Okudaira et al., 2017; Degli Alessandrini et al., 2017).

At low shear strain and identical $P-T$ conditions, the small difference in mineral reactions between the Fe-rich opx + plag and Mg-rich opx + plag assemblages induces clear differences in mechanical strength at peak stress and during subsequent weakening. These observations are crucial as shear zones are known to represent preferential regions for mineral reactions to occur, either owing to deformation (e.g., Brodie, 1980) or to the presence of fluids (e.g., Etheridge et al., 1983) during protracted shearing (e.g., Brodie, 1980; Philippot and Kienast, 1989; Newman et al., 1999). Thus, local spatial variations in mineral reactions can induce gradients in deformation due to sufficient differences in the mechanical behavior to localize strain (e.g., Holyoke and Tullis, 2006a, b). In addition, our observations suggest that the mechanical strength at peak stress is controlled by the ability of the material to react and connect to the weak material, not necessarily by the strength of the reaction products. In fact, the Fe-rich opx + plag assemblages produce intrinsically stronger reaction products (more amphibole) than 
the fine-grained mixed aggregates and layers in the $\mathrm{Mg}$ rich opx + plag assemblages, and yet Fe-rich opx + plag assemblages are weaker at low shear strain because they react faster. It is speculated that this difference in reaction kinetics is in part controlled by the amount of $\mathrm{H}_{2} \mathrm{O}$ present. The higher $\mathrm{H}_{2} \mathrm{O}$ content in the Fe-rich opx + plag assemblages may have had a positive effect on the kinetics of reaction. This aspect of the influence of $\mathrm{H}_{2} \mathrm{O}$ availability on the strength of materials is important because shear zones have long been recognized as a preferred locus for fluid migration (e.g., Austrheim, 1987; Newton, 1990; Selverstone et al., 1991; Gueydan et al., 2004; Angiboust et al., 2011), particularly due to the development of syn-kinematic porosity resulting from dilatancy at grain boundaries (Tullis et al., 1996), creep cavitation (Fusseis et al., 2009; Menegon et al., 2015; Précigout and Stünitz, 2016; Précigout et al., 2019), or from dehydration reactions and associated fracturing (Plümper et al., 2017).

Our results suggest that small initial differences in mineral reactions in natural materials can trigger strain localization and lead to large differences in mechanical strength, regardless of the intrinsic strength of the reaction products. These observations mainly apply to the initiation and early stages of shear zone formation, as once the incipient stages of strain localization and weakening are initiated, additional mechanisms are involved and control the development of the shear zones in space and time.

The development of natural shear zones is commonly arranged into distinctive monophase layers (e.g., Berthé et al., 1979; Gapais, 1989) and/or polyphase mixtures (e.g., Fliervoet et al., 1997; Keller et al., 2004; Warren and Hirth, 2006; Kanagawa et al., 2008; Raimbourg et al., 2008; Okudaira et al., 2015) that may be found in the same shear zone as alternating layers (e.g., Kenkmann and Dresen, 2002; Kilian et al., 2011; Oliot et al., 2014; Mansard et al., 2018). In our case, the progressive deformation of two-phase assemblages also shows the development of (1) a strongly localized polyphase high-strain zone associated with a significant weakening after peak stress (Mg-rich assemblages) and (2) only locally connected $\sigma$-clast bands that do not induce major weakening (Fe-rich opx + plag and amph + plag assemblages). Strain localization into reaction-derived fine-grained mixtures is also well-documented in nature with the dominance of diffusion-accommodated GBS and/or DPC mechanisms (e.g., Newman et al., 1999; Handy and Stünitz, 2002; Kanagawa et al., 2008; Okudaira et al., 2015) and is expected to promote major rheological weakening (e.g., Fliervoet et al., 1997; Svahnberg and Piazolo, 2013; Warren and Hirth, 2006; Platt, 2015). The development of amph-rich $\sigma$ shaped aggregates and layers, notably through dissolution and precipitation processes, is also commonly documented in middle to lower crustal banded mylonites (e.g., Berger and Stünitz, 1996; Imon et al., 2002, 2004; Baratoux et al., 2005; Getsinger et al., 2013; Elyaszadeh et al., 2018; Giuntoli et al., 2018).
When applied to natural shear zones, our results suggest that (1) the ability of minerals to react controls the portions of rocks that deform, and (2) minor chemical and mineralogical variations (including the $\mathrm{H}_{2} \mathrm{O}$ available for reaction) can considerably modify the strength of deformed assemblages. Then, significant strain localization and partitioning at high shear strain, expressed by the development of interconnected high-strain zones (Mg-rich opx + plag), illustrate that finegrained polyphase mixed zones can become weaker than coarse-grained, poorly connected ones (Fe-rich opx + plag and amph + plag). These results emphasize the importance of strain partitioning, grain size reduction, and interconnectivity of weak material as primary controls of lithospheric strength. This also suggests that the rheology of mafic rocks, which constitute a large part of the oceanic crust and may be one of the main components of the lower continental crust, cannot be summarized as being rheologically controlled by monophase materials (e.g., Dimanov and Dresen, 2005).

\section{Conclusions}

Shear deformation experiments with monophase and polyphase assemblages show a clear relationship between deformation and mineral reactions. A greater volume of reaction products is documented with increasing strain. This study shows that the premise of mineral reaction and strain localization has a major impact on sample strength because it conditions the resistance of the assemblage at low shear strain. Indeed, the Fe-rich opx + plag assemblages deform at lower stresses than the Mg-rich opx + plag assemblages because they react faster at early stages of experimentation. Thus, chemically similar assemblages may have significantly different strength development depending on the ability of these minerals to react. It is suggested that the availability of $\mathrm{H}_{2} \mathrm{O}$, among other factors such as mineral composition, has a positive effect on the kinetics of reaction. With increasing strain, there are two very contrasting pathways in the material evolution, controlled by the properties of the reaction: in one case (Fe-opx + plag and amph + plag assemblages), the reaction products (mostly amphibole) have elongated grain shapes, a larger grain size, and poor connectivity. As a result, they do not show significant weakening. In such a case, the reaction products are only partially connected, the material deforms by grain-scale DPC, and the strength of the bulk sample is stable so the feedback effect of deformation on the reaction is limited. In the other cases (Mg-rich opx + plag and pure amph assemblages), the fine-grained, intensely mixed reaction products of equant grains weaken considerably during the experiment and end up much weaker than the initial material. The mechanically weak zone of reaction product deforms by GBS-dominated DPC and tends to form an interconnected zone that leads to the weakening of the bulk sample, and the drastic increase in the proportion of reaction products with strain suggests a large feed- 
back effect. Overall, the value of the initial peak stress (that is responsible for determining where strain will start localizing) and the large weakening associated with the formation of fine-grained products (that determines whether shear bands thicken or not) seem to be mainly controlled by the chemical reactions.

Data availability. Experimental data were processed using a MATLAB-based program inspired by the "rig" program of Dr. Matej Pec (Pec et al., 2016) and available at https://sites.google. com/site/jacquesprecigout/telechargements-downloads, last access: 5 August 2020.

Author contributions. NM, HS, HR, and JP designed the experiments. NM and JP carried them out. NM carried out the various analyses after the experiments (e.g., SEM, EPMA). AP worked on the thermodynamic modeling part, while LN contributed to the FTIR data acquisition. NM prepared the paper with contributions from all co-authors.

Competing interests. The authors declare that they have no conflict of interest.

Acknowledgements. This work has received funding from the European Research Council (ERC) under the Seventh Framework Programme of the European Union (ERC Advanced Grant, grant agreement no. 290864, RHEOLITH), Labex VOLTAIRE (ANR-10LABX-100-01), and the project FluPrism (CNRS INSU, funding program SYSTER). We gratefully acknowledge the help provided by Patricia Benoist and Ida Di Carlo for analytical support, Sylvain Janiec for the preparation of thin sections, and Kai Neufeld for EBSD data acquisition. The authors wish to thank Mark Zimmerman for generously providing the Damaping peridotite and Laurent Arbaret for the Massif Central amphibolite material. We also appreciate thorough and constructive reviews by Luca Menegon and Jolien Linckens. We would like to thank Florian Fusseis for editorial handling.

Financial support. This research has been supported by the European Research Council (ERC) under the Seventh Framework Programme of the European Union (ERC Advanced Grant, grant agreement no. 290864, RHEOLITH), Labex VOLTAIRE (grant no. ANR-10-LABX-100-01), EquipEx PLANEX (grant no. ANR-11EQPX-0036), and the project FluPrism (CNRS INSU, funding program SYSTER).

Review statement. This paper was edited by Florian Fusseis and reviewed by Luca Menegon and Jolien Linckens.

\section{References}

Angiboust, S., Agard, P., Raimbourg, H., Yamato, P. and Huet, B.: Subduction interface processes recorded by eclogite-facies shear zones (Monviso, W. Alps), Lithos, 127, 222-238, https://doi.org/10.1016/j.lithos.2011.09.004, 2011.

Ashby, M. and Verrall, R.: Diffusion-accommodated flow and superplasticity, Acta Metall., 21, 149-163, https://doi.org/10.1016/0001-6160(73)90057-6, 1973.

Austrheim, H.: Eclogitization of lower crustal granulites by fluid migration through shear zones, Earth Planet. Sci. Lett., 81, 221232, https://doi.org/10.1016/0012-821X(87)90158-0, 1987.

Baratoux, L., Schulmann, K., Ulrich, S., and Lexa, O.: Contrasting microstructures and deformation mechanisms in metagabbro mylonites contemporaneously deformed under different temperatures (c. $650 \mathrm{C}$ and c. $750 \mathrm{C}$ ), Geol. Soc. London, Spec. Publ., 243, 97-125, https://doi.org/10.1144/GSL.SP.2005.243.01.09, 2005.

Barreiro, J. G., Lonardelli, I., Wenk, H. R., Dresen, G., Rybacki, E., Ren, Y., and Tomé, C. N.: Preferred orientation of anorthite deformed experimentally in Newtonian creep, Earth Planet. Sci. Lett., 264, 188-207, https://doi.org/10.1016/J.EPSL.2007.09.018, 2007.

Behrmann, J. H.: Crystal plasticity and superplasticity in quartzite; A natural example, Tectonophysics, 115, 101-129, https://doi.org/10.1016/0040-1951(85)90102-7, 1985.

Bell, D. R., Ihinger, P. D., and Rossman, G. R.: Quantitative analysis of trace $\mathrm{OH}$ in garnet and pyroxenes, Am. Mineral., 80, 465-474, https://doi.org/10.2138/am-1995-5-607, 1995.

Bercovici, D. and Ricard, Y.: Mechanisms for the generation of plate tectonics by two-phase grain-damage and pinning, Phys. Earth Planet. Inter., 202-203, 27-55, https://doi.org/10.1016/J.PEPI.2012.05.003, 2012.

Berger, A. and Stünitz, H.: Deformation mechanisms and reaction of hornblende: examples from the Bergell tonalite (Central Alps), Tectonophysics, 257, 149-174, https://doi.org/10.1016/00401951(95)00125-5, 1996.

Berthé, D., Choukroune, P., and Jegouzo, P.: Orthogneiss, mylonite and non coaxial deformation of granites: the example of the South Armorican Shear Zone, J. Struct. Geol., 1, 31-42, https://doi.org/10.1016/0191-8141(79)90019-1, 1979.

Bons, P. D. and Den Brok, B.: Crystallographic preferred orientation development by dissolution-precipitation creep, J. Struct. Geol., 22, 1713-1722, 2000.

Borg, I. and Handin, J.: Experimental deformation of crystalline rocks, Tectonophysics, 3, 249-367, https://doi.org/10.1016/0040-1951(66)90019-9, 1966.

Boullier, A. M. and Gueguen, Y.: SP-Mylonites: Origin of some mylonites by superplastic flow, Contrib. Mineral. Petrol., 50, 93104, https://doi.org/10.1007/BF00373329, 1975.

Brander, L., Svahnberg, H., and Piazolo, S.: Brittle-plastic deformation in initially dry rocks at fluid-present conditions: Transient behaviour of feldspar at mid-crustal levels, Contrib. Mineral. Petrol., 163, 403-425, https://doi.org/10.1007/s00410-0110677-5, 2012.

Brodie, K. H.: Variations in mineral chemistry across a shear zone in phlogopite peridotite, J. Struct. Geol., 2, 265-272, https://doi.org/10.1016/0191-8141(80)90059-0, 1980.

Brodie, K. H. and Rutter, E. H.: On the Relationship between Deformation and Metamorphism, with Special Reference to the Be- 
havior of Basic Rocks, pp. 138-179, Springer, New York, NY, 1985.

Brodie, K. H. and Rutter, E. H.: The role of transiently finegrained reaction products in syntectonic metamorphism: natural and experimental examples, Can. J. Earth Sci., 24, 556-564, https://doi.org/10.1139/e87-054, 1987.

Brodie, K. H., Rutter, E. H., and Evans, P.: On the structure of the Ivrea-Verbano Zone (northern Italy) and its implications for present-day lower continental crust geometry, Terra Nov., 4, 3440, https://doi.org/10.1111/j.1365-3121.1992.tb00448.x, 1992.

Bunge, H.-J.: Texture analysis in materials science?: mathematical methods, Butterworths, London, ISBN: 978-0-408-10642-9, 1982.

Bystricky, M. and Mackwell, S.: Creep of dry clinopyroxene aggregates, J. Geophys. Res.-Solid Earth, 106, 13443-13454, https://doi.org/10.1029/2001JB000333, 2001.

Bystricky, M., Lawlis, J., Mackwell, S., Heidelbach, F., and Raterron, P.: High-temperature deformation of enstatite aggregates, J. Geophys. Res.-Solid Earth, 121, 6384-6400, https://doi.org/10.1002/2016JB013011, 2016.

Coe, R. S.: The thermodynamic effect of shear stress on the orthoclino inversion in enstatite and other coherent phase transitions characterized by a finite simple shear, Contrib. Mineral. Petrol., 26, 247-264, https://doi.org/10.1007/BF00373203, 1970.

Coe, R. S. and Kirby, S. H.: The orthoenstatite to clinoenstatite transformation by shearing and reversion by annealing: Mechanism and potential applications, Contrib. Mineral. Petrol., 52, 29-55, https://doi.org/10.1007/BF00378000, 1975.

Connolly, J. A. D.: The geodynamic equation of state: What and how, Geochemistry, Geophys. Geosystems, 10, Q10014,, https://doi.org/10.1029/2009GC002540, 2009.

Dale, J., Powell, R., White, R. W., Elmer, F. L., and Holland, T. J. B.: A thermodynamic model for $\mathrm{Ca}-\mathrm{Na}$ clinoamphiboles in Na2O-CaO-FeO-MgO-Al2O3-SiO2- $\mathrm{H}_{2} \mathrm{O}-\mathrm{O}$ for petrological calculations, J. Metamorph. Geol., 23, 771-791, https://doi.org/10.1111/j.1525-1314.2005.00609.x, 2005.

Degli Alessandrini, G., Menegon, L., Malaspina, N., Dijkstra, A. H., and Anderson, M. W.: Creep of mafic dykes infiltrated by melt in the lower continental crust (Seiland Igneous Province, Norway), Lithos, 274-275, 169-187, https://doi.org/10.1016/j.lithos.2016.12.030, 2017.

Dell'Angelo, L. N. and Tullis, J.: Textural and mechanical evolution with progressive strain in experimentally deformed aplite, Tectonophysics, 256, 57-82, https://doi.org/10.1016/00401951(95)00166-2, 1996.

De Ronde, A. A. and Stünitz, H.: Deformation-enhanced reaction in experimentally deformed plagioclase-olivine aggregates, Contrib. Mineral. Petrol., 153, 699-717, https://doi.org/10.1007/s00410-006-0171-7, 2007.

De Ronde, A. A., Heilbronner, R., Stünitz, H., and Tullis, J.: Spatial correlation of deformation and mineral reaction in experimentally deformed plagioclase-olivine aggregates, Tectonophysics, 389, 93-109, https://doi.org/10.1016/j.tecto.2004.07.054, 2004.

De Ronde, A. A., Stünitz, H., Tullis, J., and Heilbronner, R.: Reaction-induced weakening of plagioclaseolivine composites, Tectonophysics, 409, 85-106, https://doi.org/10.1016/j.tecto.2005.08.008, 2005.

Dimanov, A. and Dresen, G.: Rheology of synthetic anorthite-diopside aggregates: Implications for ductile shear zones, J. Geophys. Res.-Solid Earth, 110, 1-24, https://doi.org/10.1029/2004JB003431, 2005.

Dimanov, A., Lavie, M. P., Dresen, G., Ingrin, J., and Jaoul, O.: Creep of polycrystalline anorthite and diopside, J. Geophys. Res.-Solid Earth, 108, 2061, https://doi.org/10.1029/2002JB001815, 2003.

Dimanov, A., Rybacki, E., Wirth, R., and Dresen, G.: Creep and strain-dependent microstructures of synthetic anorthitediopside aggregates, J. Struct. Geol., 29, 1049-1069, https://doi.org/10.1016/J.JSG.2007.02.010, 2007.

Elyaszadeh, R., Prior, D. J., Sarkarinejad, K., and Mansouri, H.: Different slip systems controlling crystallographic preferred orientation and intracrystalline deformation of amphibole in mylonites from the Neyriz mantle diapir, Iran, J. Struct. Geol., 107, 38-52, https://doi.org/10.1016/j.jsg.2017.11.020, 2018.

Etheridge, M. A., Wall, V. J., and Vernon, R. H.: The role of the fluid phase during regional metamorphism and deformation, $\mathrm{J}$. Metamorph. Geol., 1, 205-226, https://doi.org/10.1111/j.15251314.1983.tb00272.x, 1983.

Farla, R. J. M., Karato, S.-I., and Cai, Z.: Role of orthopyroxene in rheological weakening of the lithosphere via dynamic recrystallization, P. Natl. Acad. Sci. USA, 110, 16355-16360, https://doi.org/10.1073/pnas.1218335110, 2013.

Fitz Gerald, J. and Stünitz, H.: Deformation of granitoids at low $\mathrm{m} \sim$ tamo $\sim \mathrm{ic}$ grade. I: Reactions and grain size reduction, Elsevier Sci. Publ. B.V, 221, 269-297, https://doi.org/10.1016/0040-1951(93)90164-F, 1993.

Fliervoet, T. F. and White, S. H.: Quartz deformation in a very fine grained quartzo-feldspathic mylonite: a lack of evidence for dominant grain boundary sliding deformation, J. Struct. Geol., 17, 1095-1109, https://doi.org/10.1016/0191-8141(95)00007-Z, 1995.

Fliervoet, T. F., White, S. H., and Drury, M. R.: Evidence for dominant grain-boundary sliding deformation in greenschistand amphibolite-grade polymineralic ultramylonites from the Redbank Deformed Zone, Central Australia, J. Struct. Geol., 19, 1495-1520, https://doi.org/10.1016/S0191-8141(97)00076X, 1997.

Fusseis, F., Regenauer-Lieb, K., Liu, J., Hough, R. M., and De Carlo, F.: Creep cavitation can establish a dynamic granular fluid pump in ductile shear zones, Nature, 459, 974-977, https://doi.org/10.1038/nature08051, 2009.

Gapais, D.: Shear structures within deformed granites: Mechanical and thermal indicators, Geology, 17, 1144-1147, 1989.

Getsinger, A. J. and Hirth, G.: Amphibole fabric formation during diffusion creep and the rheology of shear zones, Geology, 42, 535-538, https://doi.org/10.1130/G35327.1, 2014.

Getsinger, A. J., Hirth, G., Stünitz, H., and Goergen, E. T.: Influence of water on rheology and strain localization in the lower continental crust, Geochem. Geophys. Geosy., 14, 2247-2264, https://doi.org/10.1002/ggge.20148, 2013.

Gilgannon, J., Fusseis, F., Menegon, L., Regenauer-Lieb, K., and Buckman, J.: Hierarchical creep cavity formation in an ultramylonite and implications for phase mixing, Solid Earth, 8, 11931209, https://doi.org/10.5194/se-8-1193-2017, 2017.

Giuntoli, F., Menegon, L., and Warren, C. J.: Replacement reactions and deformation by dissolution and precipitation processes in amphibolites, J. Metamorph. Geol., 36, 1263-1286, https://doi.org/10.1111/jmg.12445, 2018. 
Gueydan, F., Leroy, Y. M., and Jolivet, L.: Mechanics of low-angle extensional shear zones at the brittle-ductile transition, J. Geophys. Res.-Solid Earth, 109, 1-16, https://doi.org/10.1029/2003JB002806, 2004.

Handy, M. R.: Flow laws for rocks containing two non-linear viscous phases: A phenomenological approach, J. Struct. Geol., 16, 287-301, https://doi.org/10.1016/0191-8141(94)90035-3, 1994.

Handy, M. R. and Stünitz, H.: Strain localization by fracturing and reaction weakening - a mechanism for initiating exhumation of subcontinental mantle beneath rifted margins, Geol. Soc. London, Spec. Publ., 200, 387-407, https://doi.org/10.1144/GSL.SP.2001.200.01.22, 2002.

Harigane, Y., Michibayashi, K., and Ohara, Y.: Shearing within lower crust during progressive retrogression: Structural analysis of gabbroic rocks from the Godzilla Mullion, an oceanic core complex in the Parece Vela backarc basin, Tectonophysics, 457, 183-196, https://doi.org/10.1016/j.tecto.2008.06.009, 2008.

Herwegh, M. and Berger, A.: Deformation mechanisms in second-phase affected microstructures and their energy balance, J. Struct. Geol., 26, 1483-1498, https://doi.org/10.1016/J.JSG.2003.10.006, 2004.

Herwegh, M., Linckens, J., Ebert, A., Berger, A., and Brodhag, S. H.: The role of second phases for controlling microstructural evolution in polymineralic rocks: A review, J. Struct. Geol., 33, 1728-1750, https://doi.org/10.1016/j.jsg.2011.08.011, 2011.

Holland, T. J. B. and Powell, R.: An internally consistent thermodynamic data set for phases of petrological interest, J. Metamorph. Geol., 16, 309-343, https://doi.org/10.1111/j.15251314.1998.00140.x, 1998.

Holyoke, C. W. and Tullis, J.: Formation and maintenance of shear zones, Geology, 34, 105-108, https://doi.org/10.1130/G22116.1, 2006 .

Holyoke, C. W. and Tullis, J.: Mechanisms of weak phase interconnection and the effects of phase strength contrast on fabric development, J. Struct. Geol., 28, 621-640, https://doi.org/10.1016/j.jsg.2006.01.008, 2006b.

Imon, R., Okudaira, T., and Fujimoto, A.: Dissolution and precipitation processes in deformed amphibolites: an example from the ductile shear zone of the Ryoke metamorphic belt, SW Japan, J. Metamorph. Geol., 20, 297-308, https://doi.org/10.1046/j.15251314.2002.00367.x, 2002.

Imon, R., Okudaira, T., and Kanagawa, K.: Development of shapeand lattice-preferred orientations of amphibole grains during initial cataclastic deformation and subsequent deformation by dissolution-precipitation creep in amphibolites from the Ryoke metamorphic belt, SW Japan, J. Struct. Geol., 26, 793-805, https://doi.org/10.1016/j.jsg.2003.09.004, 2004.

Johnson, E. A.: Water in nominally anhydrous crustal minerals: Speciation, concentration, and geologic significance, in: Water in Nominally Anhydrous Minerals, vol. 62, pp. 117-154, Walter de Gruyter GmbH, 2006.

Johnson, E. A. and Rossmann, G. R.: The concentration and speciation of hydrogen in feldspars using FTIR and 1H MAS NMR spectroscopy, Am. Mineral., 88, 901-911, https://doi.org/10.2138/am-2003-5-620, 2003.

Johnson, E. A. and Rossman, G. R.: A survey of hydrous species and concentrations in igneous feldspars, Am. Mineral., 89, 586600, https://doi.org/10.2138/am-2004-0413, 2004.
Jolivet, L. and Miyashita, S.: The Hidaka Shear Zone (Hokkaido, Japan): Genesis during a right-lateral strike-slip movement, Tectonics, 4, 289-302, https://doi.org/10.1029/TC004i003p00289, 1985.

Jordan, P.: The rheology of polymineralic rocks - an approach, Geol. Rundschau, 77, 285-294, https://doi.org/10.1007/BF01848690, 1988.

Kanagawa, K., Shimano, H., and Hiroi, Y.: Mylonitic deformation of gabbro in the lower crust: A case study from the Pankenushi gabbro in the Hidaka metamorphic belt of central Hokkaido, Japan, J. Struct. Geol., 30, 1150-1166, https://doi.org/10.1016/j.jsg.2008.05.007, 2008.

Keller, L. M., Abart, R., Stünitz, H., and De Capitani, C.: Deformation, mass transfer and mineral reactions in an eclogite facies shear zone in a polymetamorphic metapelite (Monte Rosa nappe, western Alps), J. Metamorph. Geol., 22, 97-118, https://doi.org/10.1111/j.1525-1314.2004.00500.x, 2004.

Kenkmann, T. and Dresen, G.: Dislocation microstructure and phase distribution in a lower crustal shear zone - An example from the Ivrea-Zone, Italy, Int. J. Earth Sci., 91, 445-458, https://doi.org/10.1007/s00531-001-0236-9, 2002.

Kerrich, R., Allison, I., Barnett, R. L., Moss, S., and Starkey, J.: Microstructural and chemical transformations accompanying deformation of granite in a shear zone at Miéville, Switzerland; with implications for stress corrosion cracking and superplastic flow, Contrib. Mineral. Petrol., 73, 221-242, https://doi.org/10.1007/BF00381442, 1980.

Kilian, R., Heilbronner, R., and Stünitz, H.: Quartz grain size reduction in a granitoid rock and the transition from dislocation to diffusion creep, J. Struct. Geol., 33, 1265-1284, https://doi.org/10.1016/j.jsg.2011.05.004, 2011.

Knipe, R.: Deformation mechanisms - recognition from natural tectonites, J. Struct. Geol., 11, 127-146, https://doi.org/10.1016/0191-8141(89)90039-4, 1989.

Kohlstedt, D. L., Evans, B., and Mackwell, S. J.: Strength of the lithosphere: Constraints imposed by laboratory experiments, J. Geophys. Res.-Solid Earth, 100, 17587-17602, https://doi.org/10.1029/95JB01460, 1995.

Kruse, R. and Stünitz, H.: Deformation mechanisms and phase distribution in mafic high-temperature mylonites from the Jotun Nappe, southern Norway, Tectonophysics, 303, 223-249, https://doi.org/10.1016/S0040-1951(98)00255-8, 1999.

Langdon, T. G.: Grain boundary sliding revisited: Developments in sliding over four decades, J. Mater. Sci., 41, 597-609, https://doi.org/10.1007/s10853-006-6476-0, 2006.

Linckens, J., Herwegh, M., Müntener, O., and Mercolli, I.: Evolution of a polymineralic mantle shear zone and the role of second phases in the localization of deformation, J. Geophys. Res.-Solid Earth, 116, B06210, https://doi.org/10.1029/2010JB008119, 2011.

Linckens, J., Herwegh, M., and Müntener, O.: Small quantity but large effect - How minor phases control strain localization in upper mantle shear zones, Tectonophysics, 643, 26-43, https://doi.org/10.1016/j.tecto.2014.12.008, 2015.

Mansard, N., Raimbourg, H., Augier, R., Précigout, J., and Le Breton, N.: Large-scale strain localization induced by phase nucleation in mid-crustal granitoids of the south Armorican massif, Tectonophysics, 745, https://doi.org/10.1016/j.tecto.2018.07.022, 2018. 
Mansard, N., Stünitz, H., Raimbourg, H., and Précigout, J.: The role of deformation-reaction interactions to localize strain in polymineralic rocks: Insights from experimentally deformed plagioclase-pyroxene assemblages, J. Struct. Geol., 134, 104008, https://doi.org/10.1016/j.jsg.2020.104008, 2020.

Marti, S., Stünitz, H., Heilbronner, R., Plümper, O., and Drury, M.: Experimental investigation of the brittle-viscous transition in mafic rocks - Interplay between fracturing, reaction, and viscous deformation, J. Struct. Geol., 105, 62-79, https://doi.org/10.1016/j.jsg.2017.10.011, 2017.

Marti, S., Stünitz, H., Heilbronner, R., Plümper, O., and Kilian, R.: Syn-kinematic hydration reactions, grain size reduction, and dissolution-precipitation creep in experimentally deformed plagioclase-pyroxene mixtures, Solid Earth, 9, 9851009, https://doi.org/10.5194/se-9-985-2018, 2018.

Mehl, L. and Hirth, G.: Plagioclase preferred orientation in layered mylonites: Evaluation of flow laws for the lower crust, J. Geophys. Res., 113, B05202, https://doi.org/10.1029/2007JB005075, 2008.

Menegon, L., Fusseis, F., Stünitz, H., and Xiao, X.: Creep cavitation bands control porosity and fluid flow in lower crustal shear zones, Geology, 43, 227-230, https://doi.org/10.1130/G36307.1, 2015.

Miyazaki, T., Sueyoshi, K., and Hiraga, T.: Olivine crystals align during diffusion creep of Earth's upper mantle, Nature, 502, 321326, https://doi.org/10.1038/nature12570, 2013.

Montési, L. G. J.: Fabric development as the key for forming ductile shear zones and enabling plate tectonics, J. Struct. Geol., 50, 254-266, https://doi.org/10.1016/j.jsg.2012.12.011, 2013.

Newman, J., Lamb, W. M., Drury, M. R., and Vissers, R. L. M.: Deformation processes in a peridotite shear zone: reactionsoftening by an $\mathrm{H}_{2} \mathrm{O}$-deficient, continuous net transfer reaction, Tectonophysics, 303, 193-222, https://doi.org/10.1016/S00401951(98)00259-5, 1999.

Newton, R. C.: Fluids and shear zones in the deep crust, Tectonophysics, 182, 21-37, https://doi.org/10.1016/00401951(90)90339-A, 1990.

Newton, R. C., Charlu, T. V., and Kleppa, O. J.: Thermochemistry of the high structural state plagioclases, Geochim. Cosmochim. Acta, 44, 933-941, https://doi.org/10.1016/00167037(80)90283-5, 1980.

Nicolas, A. and Christensen, N. I.: Formation of anisotropy in upper mantle peridotites: A review, pp. 111-123, American Geophysical Union (AGU), 1987.

Okudaira, T., Jeřábek, P., Stünitz, H., and Fusseis, F.: Hightemperature fracturing and subsequent grain-size-sensitive creep in lower crustal gabbros: Evidence for coseismic loading followed by creep during decaying stress in the lower crust, J. Geophys. Res.-Solid Earth, 120, 3119-3141, https://doi.org/10.1002/2014JB011708, 2015.

Okudaira, T., Shigematsu, N., Harigane, Y., and Yoshida, K.: Grain size reduction due to fracturing and subsequent grainsize-sensitive creep in a lower crustal shear zone in the presence of a $\mathrm{CO}_{2}$-bearing fluid, J. Struct. Geol., 95, 171-187, https://doi.org/10.1016/j.jsg.2016.11.001, 2017.

Olgaard, D. L.: The role of second phase in localizing deformation, Geol. Soc. London, Spec. Publ., 54, 175-181, https://doi.org/10.1144/GSL.SP.1990.054.01.17, 1990.
Olgaard, D. L. and Evans, B.: Effect of Second-Phase Particles on Grain Growth in Calcite, J. Am. Ceram. Soc., 69, C-272-C-277, https://doi.org/10.1111/j.1151-2916.1986.tb07374.x, 1986.

Olgaard, D. L. and Evans, B.: Grain growth in synthetic marbles with added mica and water, Contrib. Mineral. Petrol., 100, 246260, https://doi.org/10.1007/BF00373591, 1988.

Oliot, E., Goncalves, P., Schulmann, K., Marquer, D., and Lexa, O.: Mid-crustal shear zone formation in granitic rocks: Constraints from quantitative textural and crystallographic preferred orientations analyses, Tectonophysics, 612-613, 63-80, https://doi.org/10.1016/j.tecto.2013.11.032, 2014.

Palazzin, G., Raimbourg, H., Stünitz, H., Heilbronner, R., Neufeld, K., and Précigout, J.: Evolution in $\mathrm{H}_{2} \mathrm{O}$ contents during deformation of polycrystalline quartz: An experimental study, J. Struct. Geol., 114, 95-110, https://doi.org/10.1016/J.JSG.2018.05.021, 2018.

Paterson, M. S.: The determination of hydroxyl by infrared adsorption in quartz, silicate glasses and similar materials., Bull. Mineral., 105, 20-29, https://doi.org/10.3406/bulmi.1982.7582, 1982.

Paterson, M. S.: Superplasticity in Geological Materials, MRS Proc., 196, 303, https://doi.org/10.1557/proc-196-303, 1990.

Paterson, M. S.: A Granular Flow Approach to Fine-Grain Superplasticity, in: Plastic Deformation of Ceramics, pp. 279-283, Springer USA, 1995.

Paterson, M. S.: Materials Science for Structural Geology, 1st ed., Springer, New York, 2013.

Pec, M., Stünitz, H., Heilbronner, R., Drury, M., and de Capitani, C.: Origin of pseudotachylites in slow creep experiments, Earth Planet. Sci. Lett., 355-356, 299-310, https://doi.org/10.1016/J.EPSL.2012.09.004, 2012a.

Pec, M., Stünitz, H., and Heilbronner, R.: Semi-brittle deformation of granitoid gouges in shear experiments at elevated pressures and temperatures, 38, 200-221, https://doi.org/10.1016/j.jsg.2011.09.001, 2012b.

Pec, M., Stünitz, H., Heilbronner, R., and Drury, M.: Semi-brittle flow of granitoid fault rocks in experiments, J. Geophys. Res.-Solid Earth, 121, 1677-1705, https://doi.org/10.1002/2015JB012513, 2016.

Philippot, P. and Kienast, J. R.: Chemical-microstructural changes in eclogite-facies shear zones (Monviso, Western Alps, north Italy) as indicators of strain history and the mechanism and scale of mass transfer, Lithos, 23, 179-200, https://doi.org/10.1016/0024-4937(89)90004-2, 1989.

Platt, J. P.: Rheology of two-phase systems: A microphysical and observational approach, J. Struct. Geol., 77, 213-227, https://doi.org/10.1016/j.jsg.2015.05.003, 2015.

Plümper, O., Botan, A., Los, C., Liu, Y., Malthe-Sørenssen, A., and Jamtveit, B.: Fluid-driven metamorphism of the continental crust governed by nanoscale fluid flow, Nat. Geosci., 10, 685-690, https://doi.org/10.1038/ngeo3009, 2017.

Powell, R. and Holland, T.: Relating formulations of the thermodynamics of mineral solid solutions: Activity modeling of pyroxenes, amphiboles, and micas, Am. Mineral., 84, 1-14, https://doi.org/10.2138/am-1999-1-201, 1999.

Précigout, J. and Hirth, G.: B-type olivine fabric induced by grain boundary sliding, Earth Planet. Sci. Lett., 395, 231-240, https://doi.org/10.1016/j.epsl.2014.03.052, 2014. 
Précigout, J. and Stünitz, H.: Evidence of phase nucleation during olivine diffusion creep: A new perspective for mantle strain localisation, Earth Planet. Sci. Lett., 455, 94-105, https://doi.org/10.1016/j.epsl.2016.09.029, 2016.

Précigout, J., Prigent, C., Palasse, L., and Pochon, A.: Water pumping in mantle shear zones, Nat. Commun., 8, 15736, https://doi.org/10.1038/ncomms15736, 2017.

Précigout, J., Stünitz, H., Pinquier, Y., Champallier, R., and Schubnel, A.: High-pressure, High-temperature Deformation Experiment Using the New Generation Griggs-type Apparatus, J. Vis. Exp., 134, e56841, https://doi.org/10.3791/56841, 2018.

Raimbourg, H., Toyoshima, T., Harima, Y., and Kimura, G.: Grain-size reduction mechanisms and rheological consequences in high-temperature gabbro mylonites of Hidaka, Japan, Earth Planet. Sci. Lett., 267, 637-653, https://doi.org/10.1016/j.eps1.2007.12.012, 2008.

Richter, B., Stünitz, H., and Heilbronner, R.: The brittle-to-viscous transition in polycrystalline quartz: An experimental study, J. Struct. Geol., 114, 1-21, https://doi.org/10.1016/j.jsg.2018.06.005, 2018.

Rubie, D. C.: Reaction-enhanced ductility: The role of solidsolid univariant reactions in deformation of the crust and mantle, Tectonophysics, 96, 331-352, https://doi.org/10.1016/00401951(83)90225-1, 1983.

Rudnick, R. L. and Fountain, D. M.: Nature and composition of the continental crust: A lower crustal perspective, Rev. Geophys., 33, 267, https://doi.org/10.1029/95RG01302, 1995.

Rutter, E. H. and Brodie, K. H.: The Permeation of Water into Hydrating Shear Zones, Adv. Phys. Geochem., 4, 242-250, 1985.

Schmid, S. M.: Microfabric studies as indicators of deformation mechanisms and flow laws operative in mountain building, Mt. Build. Process., edited by: Hsu, K. J., Academic Press, 95-110, 1982.

Schroeder, T. and John, B. E.: Strain localization on an oceanic detachment fault system, Atlantis Massif, $30^{\circ} \mathrm{N}$, Mid-Atlantic Ridge, Geochem. Geophy. Geosy., 5, Q11007, https://doi.org/10.1029/2004GC000728, 2004.

Selverstone, J., Morteani, G., and Staude, J.-M.: Fluid channelling during ductile shearing: transformation of granodiorite into aluminous schist in the Tauern Window, Eastern Alps, J. Metamorph. Geol., 9, 419-431, https://doi.org/10.1111/j.15251314.1991.tb00536.x, 1991.

Shelley, D.: Spider texture and amphibole preferred orientations, J. Struct. Geol., 16, 709-717, https://doi.org/10.1016/01918141(94)90120-1, 1994.

Skemer, P., Katayama, I., Jiang, Z., and Karato, S.: The misorientation index: Development of a new method for calculating the strength of lattice-preferred orientation, Tectonophysics, 411, 157-167, https://doi.org/10.1016/J.TECTO.2005.08.023, 2005.

Skogby, H.: Water in natural mantle minerals I: Pyroxenes, in: Water in Nominally Anhydrous Minerals, vol. 62, pp. 155-168, Walter de Gruyter GmbH, 2006.
Soret, M., Agard, P., Ildefonse, B., Dubacq, B., Prigent, C., and Rosenberg, C.: Deformation mechanisms in mafic amphibolites and granulites: record from the Semail metamorphic sole during subduction infancy, Solid Earth, 10, 1733-1755, https://doi.org/10.5194/se-10-1733-2019, 2019.

Stünitz, H. and Fitz Gerald, J. D.: Deformation of granitoids at low metamorphic grades: II. Granular flow in albite rich mylonites, Tectonophysics, 221, 299-324, https://doi.org/10.1016/00401951(93)90164-F, 1993.

Stünitz, H. and Tullis, J.: Weakening and strain localization produced by syn-deformational reaction of plagioclase, Int. J. Earth Sci., 90, 136-148, https://doi.org/10.1007/s005310000148, 2001.

Sundberg, M. and Cooper, R. F.: Crystallographic preferred orientation produced by diffusional creep of harzburgite: Effects of chemical interactions among phases during plastic flow, J. Geophys. Res.-Solid Earth, 113, B12208, https://doi.org/10.1029/2008JB005618, 2008.

Svahnberg, H. and Piazolo, S.: Interaction of chemical and physical processes during deformation at fluid-present conditions: A case study from an anorthosite-leucogabbro deformed at amphibolite facies conditions, Contrib. Mineral. Petrol., 165, 543-562, https://doi.org/10.1007/s00410-012-0822-9, 2013.

Tasaka, M., Zimmerman, M. E., and Kohlstedt, D. L.: Evolution of the rheological and microstructural properties of olivine aggregates during dislocation creep under hydrous conditions, J. Geophys. Res.-Solid Earth, 121, 92-113, https://doi.org/10.1002/2015JB012134, 2016.

Tasaka, M., Zimmerman, M. E., Kohlstedt, D. L., Stünitz, H., and Heilbronner, R.: Rheological Weakening of Olivine + Orthopyroxene Aggregates Due To Phase Mixing: Part 2. Microstructural Development, J. Geophys. Res.-Solid Earth, 122, 7597-7612, https://doi.org/10.1002/2017JB014311, 2017.

Tullis, J., Yund, R., and Farver, J.: Deformation-enhanced fluid distribution in feldspar aggregates and implications for ductile shear zones, Geology, 24, 63-66, https://doi.org/10.1130/00917613(1996)024<0063:defdif>2.3.co;2, 1996.

Vissers, R. L. M., Drury, M. R., Newman, J., and Fliervoet, T. F.: Mylonitic deformation in upper mantle peridotites of the North Pyrenean Zone (France): implications for strength and strain localization in the lithosphere, Tectonophysics, 279, 303-325, https://doi.org/10.1016/S0040-1951(97)00128-5, 1997.

Warren, J. M. and Hirth, G.: Grain size sensitive deformation mechanisms in naturally deformed peridotites, Earth Planet. Sci. Lett., 248, 423-435, https://doi.org/10.1016/j.epsl.2006.06.006, 2006.

Wenk, H.-R. and Christie, J. M.: Comments on the interpretation of deformation textures in rocks, J. Struct. Geol., 13, 1091-1110, https://doi.org/10.1016/0191-8141(91)90071-P, 1991.

Wheeler, J.: Importance of pressure solution and coble creep in the deformation of polymineralic rocks, J. Geophys. Res., 97, 4579, https://doi.org/10.1029/91JB02476, 1992. 